Prepared in cooperation with the U.S. Army Corps of Engineers and the Oregon Department of Fish and Wildlife

Development of a Study Design and Implementation Plan to Estimate Juvenile Salmon Survival in Lookout Point Reservoir and Other Reservoirs of the Willamette Project, Western Oregon
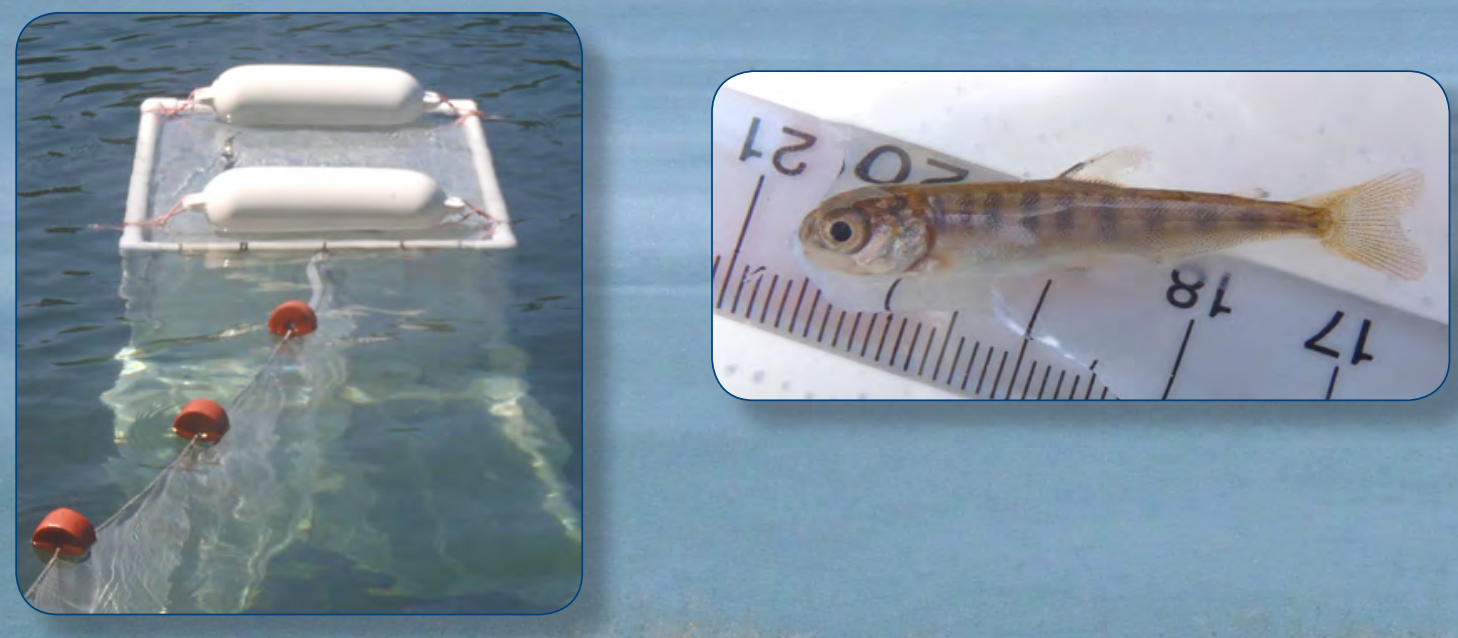

s.

- Open-File Report 2016-1211

U.S. Department of the Interior U.S. Geological Survey 
Cover: Background: Photograph of Lookout Point Reservoir, Oregon, July 22, 2010.

Insets: Floating box trap (left) and (right) a juvenile Chinook salmon (right).

Photographs by Fred Monzyk, Oregon Department of Fish and Wildlife, May 12 and May 17, 2012, respectively. 


\section{Development of a Study Design and Implementation Plan to Estimate Juvenile Salmon Survival in Lookout Point Reservoir and Other Reservoirs of the Willamette Project, Western Oregon}

By Tobias J. Kock, Russell W. Perry, Fred R. Monzyk, Adam C. Pope, and John M. Plumb

Prepared in cooperation with the U.S. Army Corps of Engineers and the Oregon Department of Fish and Wildlife

Open-File Report 2016-1211

U.S. Department of the Interior

U.S. Geological Survey 


\section{U.S. Department of the Interior \\ SALLY JEWELL, Secretary}

\section{U.S. Geological Survey \\ Suzette M. Kimball, Director}

U.S. Geological Survey, Reston, Virginia: 2016

For more information on the USGS—-the Federal source for science about the Earth, its natural and living resources, natural hazards, and the environment-visit http://www.usgs.gov/ or call 1-888-ASK-USGS (1-888-275-8747).

For an overview of USGS information products, including maps, imagery, and publications, visit http://store.usgs.gov/.

Any use of trade, firm, or product names is for descriptive purposes only and does not imply endorsement by the U.S. Government.

Although this information product, for the most part, is in the public domain, it also may contain copyrighted materials as noted in the text. Permission to reproduce copyrighted items must be secured from the copyright owner.

\section{Suggested citation:}

Kock, T.J., Perry, R.W., Monzyk, F.R., Pope, A.C., and Plumb, J.M., 2016, Development of a study design and implementation plan to estimate juvenile salmon survival in Lookout Point Reservoir and other reservoirs of the Willamette Project, western Oregon: U.S. Geological Survey Open-File Report 2016-1211, 25 p., https://doi.org/10.3133/ofr20161211. 


\section{Contents}

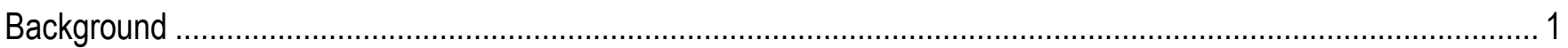

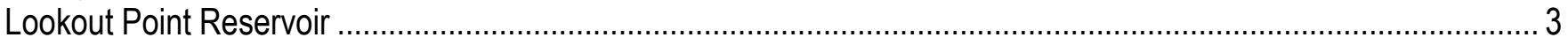

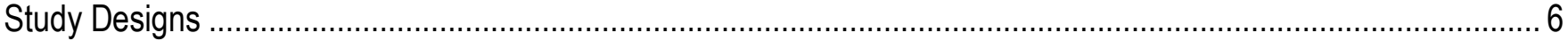

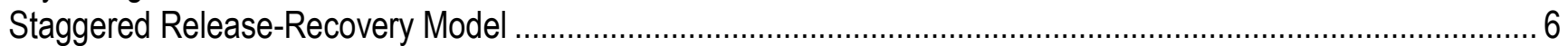

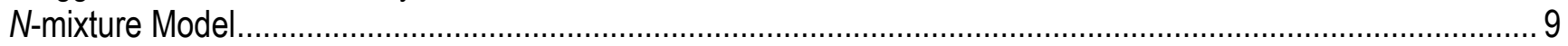

Standard $\mathrm{N}$-mixture Model with a Removal Sampling Protocol ...............................................................

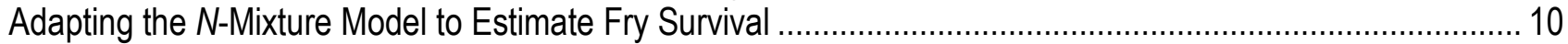

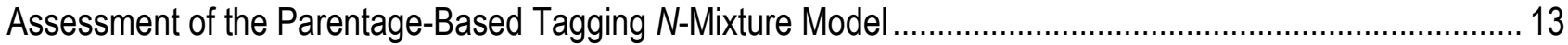

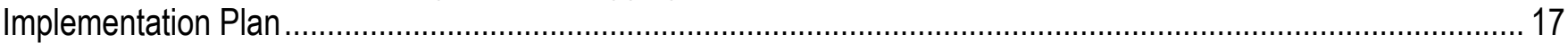

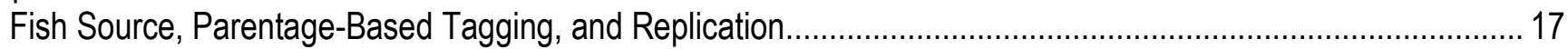

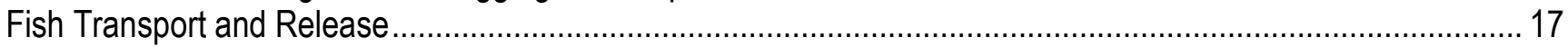

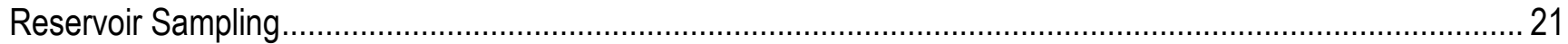

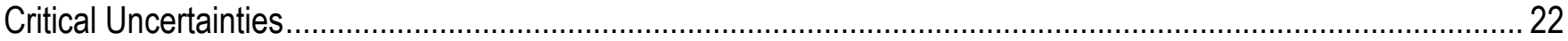

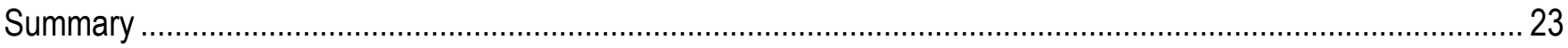

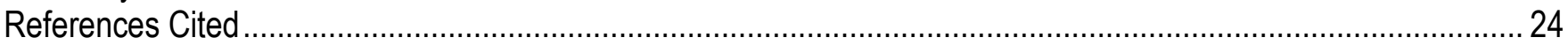

\section{Figures}

Figure 1. Map of the Middle Fork Willamette River showing Lookout Point Reservoir, Lookout Point Dam, Dexter Reservoir, and Dexter Dam, western Oregon ................................................................................. 3

Figure 2. Floodplot of water temperatures in the forebay of Lookout Point Reservoir, western Oregon, March-November 2014.

Figure 3. Graph showing fork length of juvenile Chinook salmon in Lookout Point Reservoir, western Oregon,

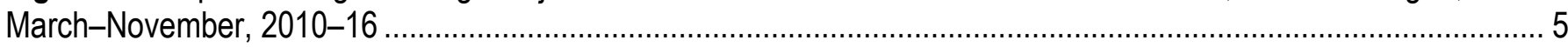

Figure 4. Schematic of the staggered release-recovery model presented by Skalski (2016) ................................... 7

Figure 5. Schematic showing study designs of staggered release-recapture study and parentage-based tagging $\mathrm{N}$-mixture model study proposed for use in Lookout Point Reservoir, western Oregon, in 2017 .................... 7

Figure 6. Posterior distributions of capture $(p)$ and survival $(S)$ probability for three simulations

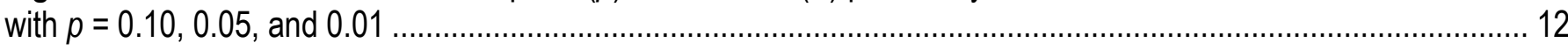

Figure 7. Posterior distributions of capture $(p)$ and survival $(S)$ probability for the simulation with two levels of capture probability and survival increasing over time.

Figure 8. Graph showing true survival relationship used to simulate capture data and estimated relationship using the parentage-based tagging $\mathrm{N}$-mixture model.

Figure 9. Orthoimage showing five release sites (white circles) for juvenile Chinook salmon in the upper part of Lookout Point Reservoir, western Oregon, during mid-April 2017

Figure 10. Photograph showing insulated fish-holding containers that will be used to transport juvenile Chinook salmon to Lookout Point Reservoir, western Oregon, during 2017.

Figure 11. Orthoimage showing five release sites (white circles) for juvenile Chinook salmon in Lookout Point Reservoir, western Oregon, during mid-June and mid-July 2017 .

Figure 12. Photographs of sampling equipment, including boat electrofishing (A), gill nets (B), floating box traps (C), and Oneida Lake traps (D), that will be used in Lookout Point Reservoir, western Oregon, 2017 


\section{Tables}

Table 1. Release groups, target release dates, number of fish in group, and target fork length, for Chinook salmon releases at Lookout Point Reservoir, western Oregon, 2017

Table 2. Estimated population of hatchery-produced juvenile Chinook salmon in Lookout Point Reservoir, western Oregon, 2014

\section{Conversion Factors}

Inch/Pound to International System of Units

\begin{tabular}{llll}
\hline & Bultiply & To obtain \\
\hline & Length & & \\
\hline foot $(\mathrm{ft})$ & 0.3048 & meter $(\mathrm{m})$ & \\
\hline
\end{tabular}

International System of Units to Inch/Pound

\begin{tabular}{|c|c|c|}
\hline Multiply & By & To obtain \\
\hline \multicolumn{3}{|c|}{ Length } \\
\hline millimeter (mm) & 0.03937 & inch (in.) \\
\hline centimeter $(\mathrm{cm})$ & 0.3937 & inch (in.) \\
\hline meter $(\mathrm{m})$ & 3.281 & foot $(\mathrm{ft})$ \\
\hline kilometer (km) & 0.6214 & mile (mi) \\
\hline \multicolumn{3}{|c|}{ Volume } \\
\hline liter (L) & 33.82 & ounce, fluid (fl. oz) \\
\hline liter (L) & 0.2642 & gallon (gal) \\
\hline \multicolumn{3}{|c|}{ Salmon growth rate } \\
\hline millimeter per day $(\mathrm{mm} / \mathrm{d})$ & 0.03937 & inch per day (in/d) \\
\hline \multicolumn{3}{|c|}{ Mass } \\
\hline $\operatorname{gram}(\mathrm{g})$ & 0.03527 & ounce, avoirdupois (oz) \\
\hline
\end{tabular}

Temperature in degrees Celsius $\left({ }^{\circ} \mathrm{C}\right)$ may be converted to degrees Fahrenheit $\left({ }^{\circ} \mathrm{F}\right)$ as ${ }^{\circ} \mathrm{F}=\left(1.8 \times{ }^{\circ} \mathrm{C}\right)+32$.

\section{Abbreviations}

ODFW Oregon Department of Fish and Wildlife

PBT parentage-based tagging

PIT-tags passive integrated transponder tags

Project Willamette Project

SFGPL Smith Farm Genetics and Performance Lab

USACE U.S. Army Corps of Engineers

WFSP Wild Fish Surrogate Program 


\title{
Development of a Study Design and Implementation Plan to Estimate Juvenile Salmon Survival in Lookout Point Reservoir and Other Reservoirs of the Willamette Project, Western Oregon
}

\author{
By Tobias J. Kock¹, Russell W. Perry', Fred R. Monzyk², Adam C. Pope'1, and John M. Plumb¹
}

\section{Background}

Estimates of juvenile salmon survival provide important monitoring data for fisheries resource managers working in impounded systems of the Western United States. Techniques have been developed to estimate survival of Pacific salmon (Oncorhynchus spp.) smolts during the past two decades, but these methods require the use of tags (passive integrated transponders [PIT-tags]) or active transmitters (radio and acoustic transmitters) and generally are applied to actively migrating fish (Skalski and others, 1998; Muir and others, 2001; Perry and others, 2010; Skalski and others, 2016). However, in places like the Willamette River Valley, Oregon, resource managers require survival estimates for fry and parr (hereinafter "fry") life stages. Estimation of fry survival is challenging because these fish are too small to be tagged with a PIT-tag or an active transmitter, and methods for estimating survival of fish in this size class have not been tested and proven.

The U.S. Army Corps of Engineers (USACE) operates the Willamette Project (hereinafter "Project") in western Oregon, which includes 13 dams and reservoirs, about $68 \mathrm{~km}$ of revetments, and several fish hatcheries. The primary purpose of the Project is flood risk management, but it also is operated to provide hydroelectricity, irrigation water, navigation, instream flows for wildlife, and recreation. The Project was determined to jeopardize Upper Willamette River spring Chinook salmon (O. tshawytscha) and winter steelhead (O. mykiss) (National Oceanic and Atmospheric Administration, 2008), which has spurred a series of studies and actions to reduce the Project effects on these populations. Fish passage is one of the key issues in the Project. Passage for adult salmon and steelhead is accomplished using trap-and-haul procedures that provide spawning opportunities in free-flowing headwaters and tributaries upstream of Project reservoirs (Sard and others, 2015). Progeny of the transported adults move downstream and spend several months rearing in Project reservoirs because passage options are limited at the high-head dams in the system (Keefer and others, 2013; Beeman and others, 2014; Kock and others, 2015; Monzyk and others, 2015). Thus, fishery managers are faced with determining whether it is better to focus on developing fish passage options at the dams, or attempting to capture fish near the head of the reservoirs. A key piece of information that will help with these

\footnotetext{
${ }^{1}$ U.S. Geological Survey.

${ }^{2}$ Oregon Department of Fish and Wildlife.
} 
decisions is understanding survival rates of salmon fry rearing in the reservoirs; high survival rates likely would result in decisions to focus on dam-based passage or collection efforts, whereas low survival rates may result in decisions to focus on collecting fish as they enter the reservoirs.

The need for study designs to estimate fry survival has been recognized and several potential options have been proposed. Skalski and others (2009) reviewed 20 fish-marking techniques and 16 release-recapture study designs to identify approaches that would be useful for estimating fry survival. They determined that 11 of the study designs were capable of estimating survival parameters, 5 of the methods required unique fish marks, the 6 remaining methods used batch-specific marks, and all potential methods required the release of more than one group of marked fish (Skalski and others, 2009). The application of these methods within the Project was further refined in October 2015, when the USACE convened the Willamette Valley Downstream Fish Passage Research, Monitoring, and Evaluation Workshop. Participants at the workshop were familiar with the Project and identified five approaches that were of interest, along with several potential locations where fry survival data were most needed. The approaches and locations that were identified in the workshop are presented in Skalski (2016).

Shortly after the workshop, the USACE requested the U.S. Geological Survey to develop a study design and implementation plan that could be used to implement a pilot study to estimate fry survival in Lookout Point Reservoir during 2017. Lookout Point Reservoir spans $16 \mathrm{~km}$ of the Middle Fork Willamette River (fig. 1), between Hills Creek Dam (not shown in fig. 1) and Dexter Dam, and is in need of downstream fish passage improvements. The reservoir supports abundant populations of several cool- and warm-water fish species that are known to prey on juvenile salmonids (Romer and Monzyk, 2014; Brandt and others, 2016). Given these factors, the assessment of fry survival in Lookout Point Reservoir was identified as a research priority by the USACE. However, assessing survival of salmon fry is challenging, so we were contracted to identify potential research approaches and to develop implementation strategies that provide the highest likelihood for success. Our goals in 2016 were to (1) assess and develop potential study designs, and (2) develop an implementation plan that could be used to evaluate fry survival in Lookout Point Reservoir during 2017.

The development of a study design and implementation plan for a pilot study in 2017 involves several components that include reviewing existing datasets and study designs, planning for and implementing juvenile salmon production to ensure that study fish are available, and developing procedures that will be used when the study is implemented. This report summarizes each of these elements and provides a recommendation to evaluate two potential study designs during a pilot effort in 2017. Additionally, procedures related to fish rearing, fish releases, and field sampling are described. 


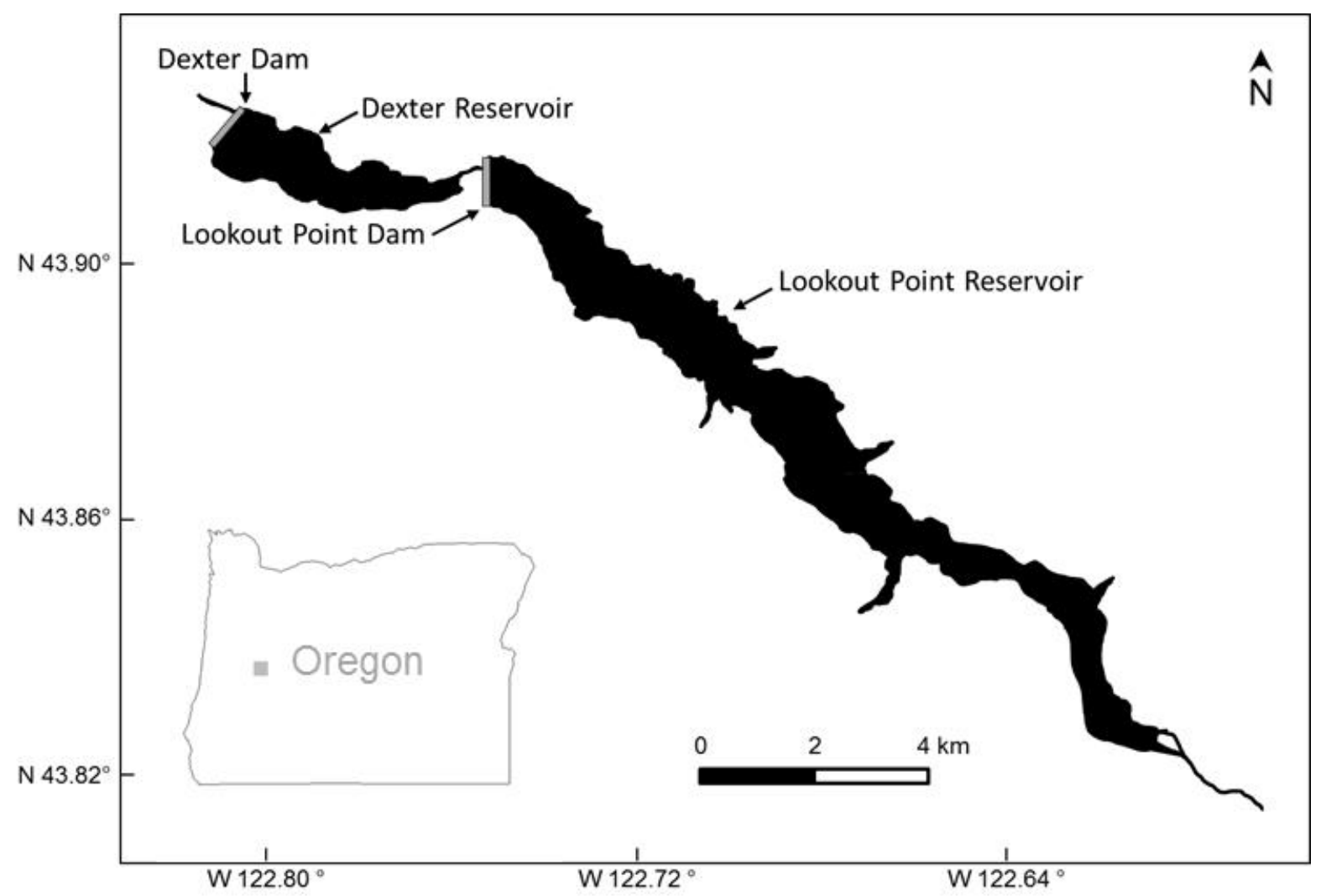

Figure 1. Map of the Middle Fork Willamette River showing Lookout Point Reservoir, Lookout Point Dam, Dexter Reservoir, and Dexter Dam, western Oregon.

\section{Lookout Point Reservoir}

Lookout Point Reservoir is located on the Middle Fork Willamette River (fig. 1). It has an overall length of about $16 \mathrm{~km}$, an average depth of $32 \mathrm{~m}$, and a maximum depth of $71 \mathrm{~m}$. Chinook salmon fry enter Lookout Point Reservoir during February-June each year, the peak occurs during April, and these fish primarily are distributed along the shorelines in the upper part of the reservoir during spring (Monzyk and others, 2015). The reservoir becomes thermally stratified in July, and Chinook salmon fry move offshore into deeper, cooler water as thermal stratification begins. Thermal stratification is substantial during July-September, when the upper $10 \mathrm{~m}$ of the water column commonly exceeds $20{ }^{\circ} \mathrm{C}$ (fig. 2). During these months, juvenile salmon generally are found in the middle and lower parts of the reservoir and reside near the thermocline, based on gill-net sampling by the Oregon Department of Fish and Wildlife (ODFW) (Monzyk and others, 2015). Thermal stratification abates during fall months when juvenile salmon exhibit a bi-modal spatial distribution with peak densities located at the upstream end of the reservoir and in the forebay of Lookout Point Dam (Monzyk and others, 2015). Growth rates in the reservoir are high. Mean fork length of Chinook salmon fry at the time of reservoir entry (March) is about $40 \mathrm{~mm}$, and fish grow to nearly $200 \mathrm{~mm}$ by November (Monzyk and others, 2015; fig. 3). Estimated growth rates during this period exceeded $0.80 \mathrm{~mm} / \mathrm{d}$ in 2012, 2013, and 2014 (Monzyk and others, 2015). Peak outmigration of juvenile salmon from Lookout Point Reservoir occurs during November, December, and January each year (Keefer and others, 2013). 


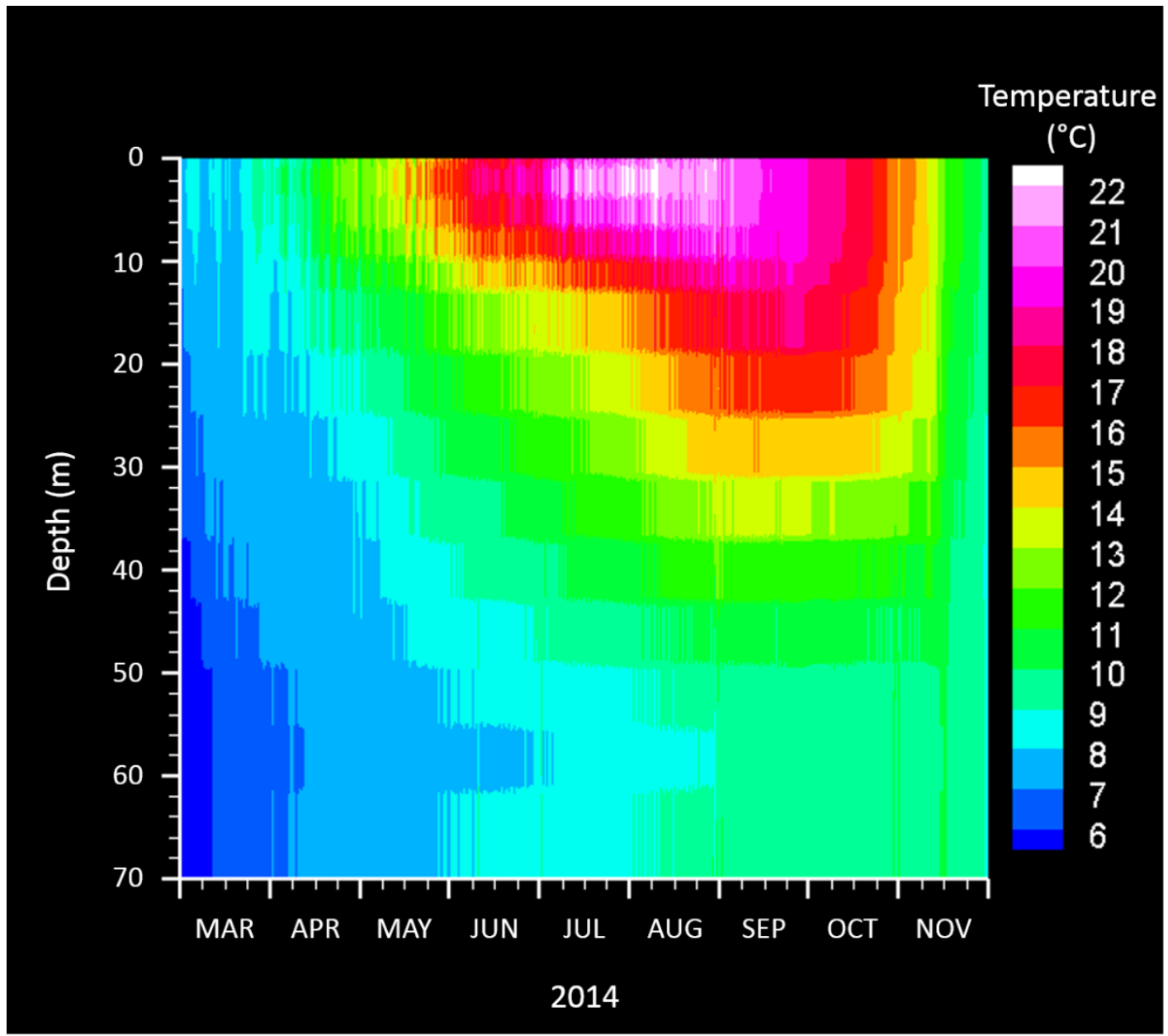

Figure 2. Floodplot of water temperatures in the forebay of Lookout Point Reservoir, western Oregon, MarchNovember 2014. 


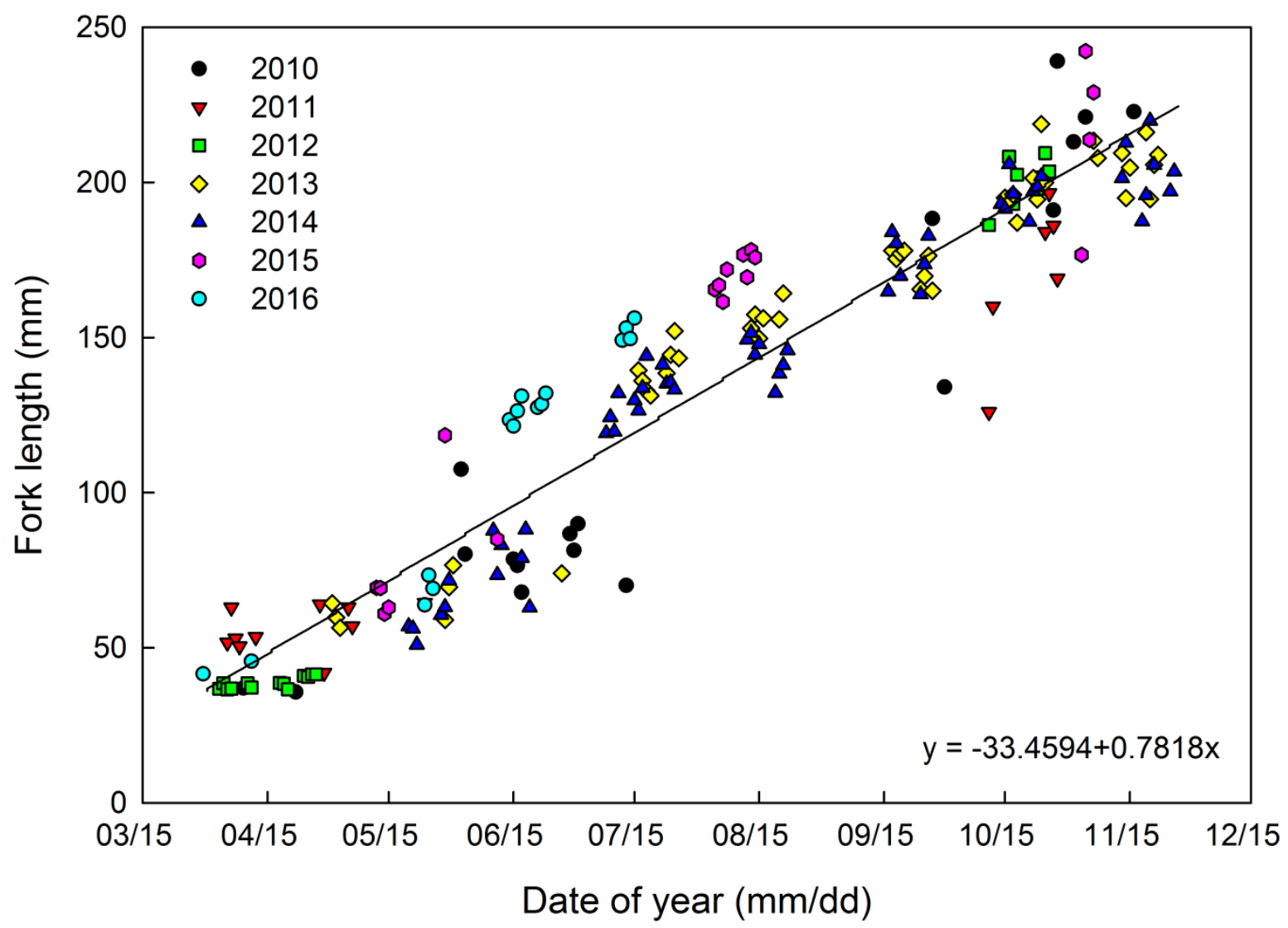

Figure 3. Graph showing fork length of juvenile Chinook salmon in Lookout Point Reservoir, western Oregon, March-November, 2010-16. Data were collected by the Oregon Department of Fish and Wildlife. Line-of-best-fit and equation for that line (obtained using linear regression) also are shown.

A substantial predator community exists in Lookout Point Reservoir. Known piscivorous fish species include white crappie (Pomoxis annularis), black crappie (P. nigromaculatus), walleye (Sander vitreus), largemouth bass (Micropterus salmoides), northern pikeminnow (Ptychocheilus oregonensis), rainbow trout (O. mykiss), and cutthroat trout (O. clarkii). The black crappie population is believed to be relatively small, and northern pikeminnow, largemouth bass, and walleye preyed primarily on fish (Brandt and others, 2016). Piscivorous fish populations in Lookout Point Reservoir appear to be heavily influenced by strong year-classes that may affect predation influences over time. Sampling conducted by the ODFW during 2013-15 showed that crappie populations currently are dominated by a strong year-class from the 2010 brood year, walleye populations are dominated by a strong year-class from the 2012 brood year, and largemouth bass populations have multiple strong year-classes (Brandt and others, 2016). Based on these data, predation rates on salmon fry likely are high in the reservoir, but the key predators may change from year to year, and predation rates are likely to change seasonally as juvenile Chinook salmon grow and metabolic demands of predators change. 
Given this information, much is known about juvenile salmon and piscivorous fish communities in Lookout Point Reservoir, and these data are important for designing a study to rigorously estimate fry survival in the reservoir. The primary objective of the study is to estimate survival during the period when fry are believed to be most vulnerable to predation. This period begins when Chinook salmon fry enter the reservoir during February-May and ends in June or July as fish grow and move offshore into cooler, deeper water. During this critical period, Chinook salmon fry are prey-sized (40-115 mm) and shoreline-oriented, which overlaps with the preferred habitats of several of the piscivorous fish species in the reservoir including crappie, largemouth bass, walleye, and northern pikeminnow (Brandt and others, 2016). The focus of this report, and the proposed pilot study in 2017, are to estimate survival of Chinook salmon fry in Lookout Point Reservoir during April-July.

\section{Study Designs}

\section{Staggered Release-Recovery Model}

The staggered release-recovery model was presented by Skalski (2016) as one approach for estimating fry survival when fish are present in Project reservoirs, but too small for marking with a PITtag. As presented, the study design includes the release of two groups of juvenile salmon $\left(R_{1}\right.$ and $\left.R_{2}\right)$ and the releases are timed to occur at the beginning $\left(R_{1}\right)$ and the end of the period of inference $\left(R_{2}\right)$. The release groups are allowed to mix for a period of time and then reservoir sampling is conducted several times to capture fish from each release group (Skalski, 2016; fig. 4). Survival is then estimated for the period of time between $R_{1}$ and $R_{2}$. The staggered release-recovery model has five primary assumptions that were summarized by Skalski (2016) and include:

1. All fish act independently.

2. Both release groups share the same recovery probabilities and intra-period survival probabilities after the second release occurs.

3. Sample sizes $R_{1}$ and $R_{2}$ are known without error.

4. Recovery numbers are correctly reported and assigned to the correct release group.

5. Fish do not lose their tags.

To evaluate fry survival in Lookout Point Reservoir, Skalski (2016) proposed to conduct the $R_{1}$ release during late March or early April and to release $R_{2}$ fish in June when fry are still oriented along the shorelines of the reservoir and vulnerable to predation (Skalski, 2016; fig. 4). Using this approach, the staggered release-recovery model would yield a survival estimate $(S ;$ fig. 4$)$ for the period of time between the release of the $R_{1}$ and mid-June, when the $R_{2}$ would be released

We are proposing to implement a modified version of the staggered release-recovery model that would include three release groups $\left(R_{1}, R_{2}\right.$ and $\left.R_{3}\right)$ and provide survival estimates during two time periods ( $S_{1}$ and $S_{2}$; fig. 5). The staggered release-recovery study design has not been field-tested, so the additional release group will allow us to obtain survival estimates from two time periods, and also may provide insights into the performance of the study design. Factors such as poor collection success (that is, low capture probability) and inadequate mixing of release groups could limit the capability of the staggered release-recovery study design, so lessons learned from the pilot effort in 2017 will be critical for assessing the approach. The third release group will increase the number of fish that are available for sampling, will provide an additional release group for assessing mixing between groups, and will allow us to estimate survival during the $S_{2}$ period. 


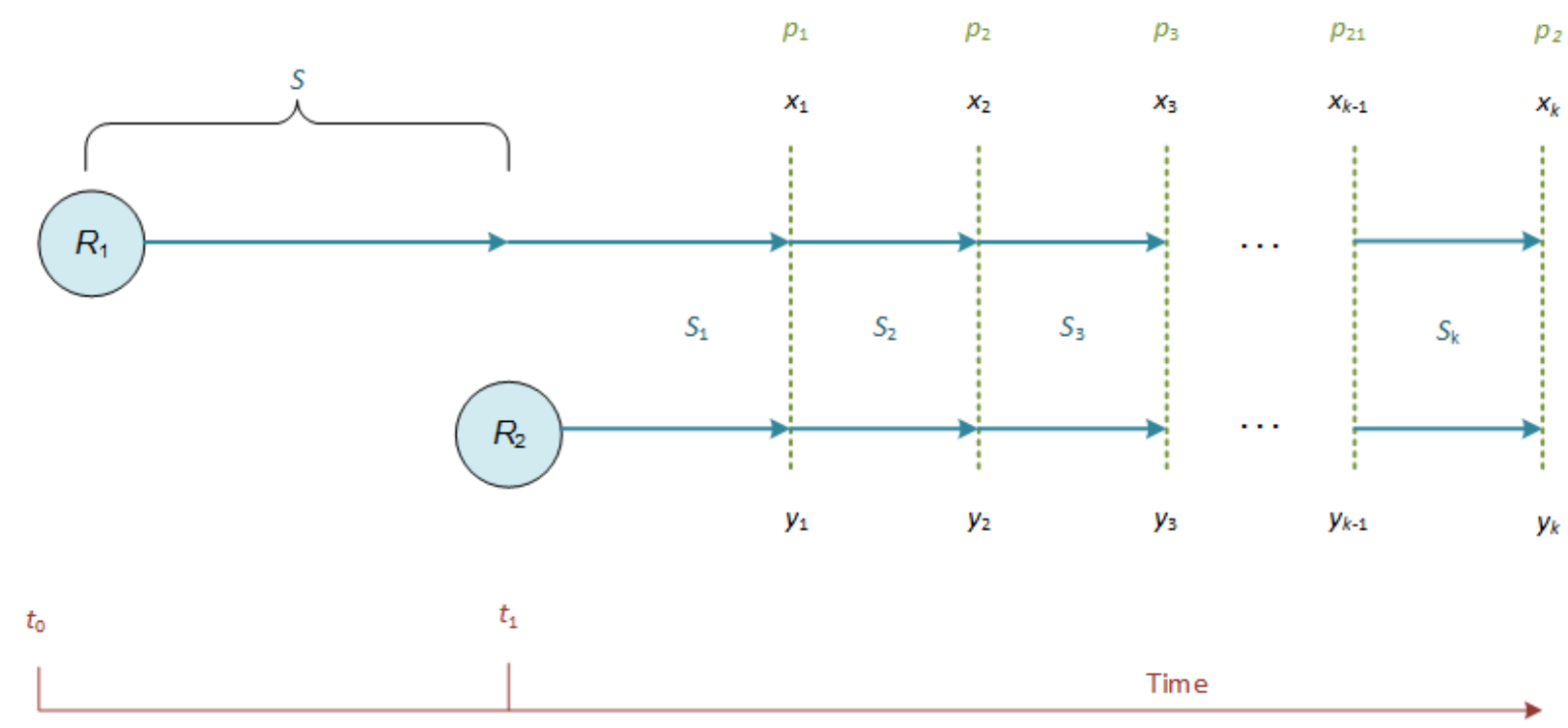

Figure 4. Schematic of the staggered release-recovery model presented by Skalski (2016). Schematic shows releases $R_{1}$ at time $t_{0}$ and $R_{2}$ at time $t_{1}$ to estimate survival $(S)$ during the intervening period. Recovery sampling occurs $k$ times following the paired releases with observed counts $x_{1}, \ldots, x_{k}$ from the $R_{1}$ release and counts $y_{1}, \ldots$, $y_{k}$ from the $R_{2}$ releases.
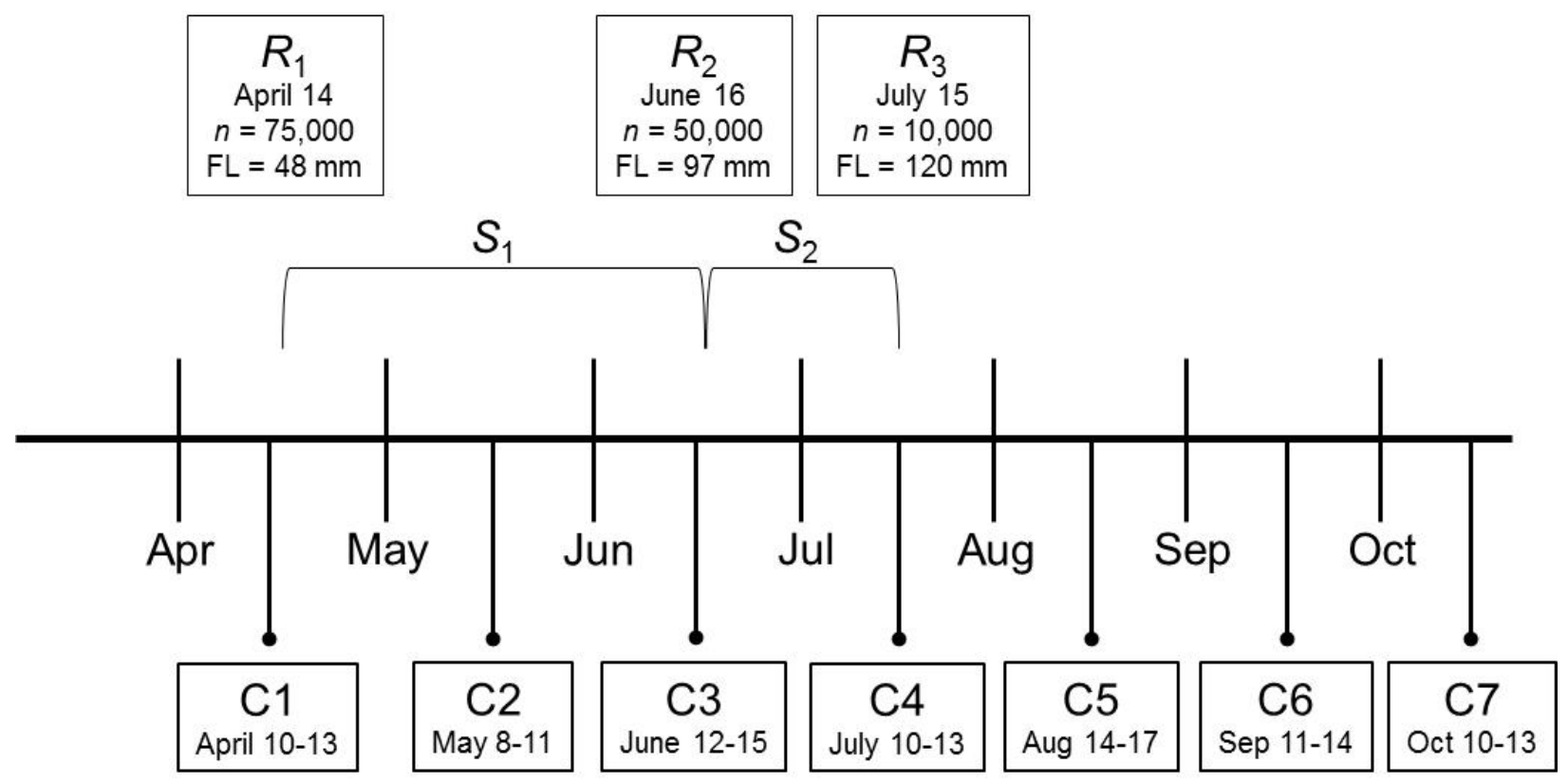

Figure 5. Schematic showing study designs of staggered release-recapture study and parentage-based tagging $\mathrm{N}$ mixture model study proposed for use in Lookout Point Reservoir, western Oregon, in 2017. Schematic includes proposed release dates of hatchery-reared juvenile Chinook salmon $\left(R_{1}, R_{2}\right.$, and $\left.R_{3}\right)$, number of fish to be released, and average size of fish (FL) in the release groups. Intervals in which survival $\left(S_{1}\right.$ and $\left.S_{2}\right)$ will be estimated and the timing of seven collection efforts (C1-C7) also are shown. Collection efforts $\mathrm{C} 1-\mathrm{C} 3$ are for the $\mathrm{N}$-mixture study design and $\mathrm{C} 4-\mathrm{C} 7$ are for the staggered release-recovery and $\mathrm{N}$-mixture study designs. 
For the 2017 pilot study, we are proposing to release groups of fish during mid-April, mid-June, and mid-July. Sample sizes for each release group were determined by examining:

1. Anticipated mortality rates of Chinook salmon fry in the reservoir;

2. Anticipated capture rates during reservoir sampling periods;

3. Effects of sample sizes on the precision of survival estimates; and

4. Logistical constraints associated with rearing fish for the study, which included the number of adults available for spawning and the space available for rearing fry prior to release.

In our initial discussions, we determined that a maximum of 135,000 Chinook salmon fry would be available for the study in 2017. Based on this constraint, we used information on anticipated reservoir survival rates, anticipated reservoir capture rates, and sample size simulations using Program SampleSize (Lady and others, 2003) to identify numbers of fish to be released in each group. The midApril release will be comprised of 75,000 fish that are about $48 \mathrm{~mm}$ long (table 1). Their release coincides with peak reservoir entry timing of naturally produced Chinook salmon fry into Lookout Point Reservoir (Monzyk and others, 2015). The mid-June release will be comprised of 50,000 fish that are about $97 \mathrm{~mm}$ long (table 1). Their release coincides with the time period when natural-origin NOR Chinook salmon begin moving offshore and are large enough that they are leaving the prey size category. Based on these releases, the first survival estimate $\left(S_{1}\right)$ will include the time period between mid-April and mid-June (fig. 5). The mid-July release will be comprised of 10,000 fish that are about $120 \mathrm{~mm}$ long (table 1). Their release will occur one month after the $R_{2}$ release, and at that time the fish should be too large to be preyed upon by most piscivorous predators in the reservoir. The second survival estimate $\left(S_{2}\right)$ will apply to the time period between mid-June and mid-July (fig. 5). Naturalorigin fry also will be present in the reservoir during 2017. A total of 687 adult spring Chinook salmon were outplanted upstream of Lookout Point Reservoir in 2016 and genetic samples were obtained from each of these fish. This will allow us to identify natural-origin fry that are captured in the reservoir, which will allow us to compare distributions of natural-origin and hatchery-origin fish. The presence of natural-origin fry will not negatively affect our study in 2017. Details for fish rearing, transport and release, and sampling methods are presented in section, "Implementation Plan."

Table 1. Release groups, target release dates, number of fish in group, and target fork length, for Chinook salmon releases at Lookout Point Reservoir, western Oregon, 2017.

\begin{tabular}{clcc}
\hline Release group & Target release date & $\begin{array}{c}\text { Number of } \\
\text { fish in group }\end{array}$ & $\begin{array}{c}\text { Target fork length } \\
\text { (millimeters) }\end{array}$ \\
\hline$R_{1}$ & April 14, 2017 & 75,000 & 48 \\
$R_{2}$ & June 16, 2017 & 50,000 & 97 \\
$R_{3}$ & July 15, 2017 & 10,000 & 120 \\
\hline
\end{tabular}




\section{$N$-mixture Model}

We developed and tested an alternative model to the staggered entry design for estimating fry survival. Our goal was to design a model that could estimate survival without using a paired release design (such as the staggered entry model) in order to avoid the strict assumptions required by the paired release model (namely, equal survival between groups after the second release). Our alternative model design is part of the class of models known as $N$-mixture models.

\section{Standard N-mixture Model with a Removal Sampling Protocol}

$N$-mixture models are a class of hierarchical models that estimate animal abundance and capture probability from repeated point counts replicated in space (Kéry and Royle, 2016). Specifically, let $y_{i j}$ represent the number of individuals sampled at site $i(i=1, \ldots, R)$ on the $j$ th sampling occasion $(j=1$, $\ldots, J)$. Under a removal sampling protocol, the sample counts arise from a multinomial distribution:

$$
y_{i 1}, \ldots, y_{i J}, N_{i}-\sum_{j=1}^{J} y_{i j} \sim \operatorname{Multinomial}\left(N_{i}, \pi_{i 1}, \ldots, \pi_{i J}, \pi_{i 0}\right)
$$

where

$$
\begin{array}{ll}
N_{i} & \text { is the abundance at site } \mathrm{i}, \\
\pi_{i j} & \text { is the probability that an individual at site } \mathrm{i} \text { is first captured on the } j \text { th sample, and } \\
\pi_{i 0} & \text { is the probability of not being captured over all } J \text { samples. }
\end{array}
$$

The primary assumption here is that the sampled population is closed to immigration, emigration, mortality, and recruitment over the $J$ samples. The probability of first capturing an individual on sample $j\left(\pi_{i j}\right)$ is a function of the per-sample capture probability:

$$
\pi_{j}=\frac{\pi_{j-1}}{p_{j-1}} p_{j}\left(1-p_{j-1}\right)
$$

where

$$
p_{j} \quad \text { is the probability of capturing an individual on the } j \text { th removal sample, and }
$$
$\pi_{1}=p_{1}$.

Although $N_{i}$ can be estimated directly for each site (Dorazio and others, 2005), $N$-mixture models leverage information across sites by assuming that distribution of site-specific abundance follows a Poisson distribution:

$$
N_{i} \sim \operatorname{Poisson}(\lambda)
$$

where

$\lambda \quad$ is the mean abundance across $R$ sites. 
The integrated likelihood function for this multinomial-Poisson mixture model has a convenient computational form that reduces to the product of conditionally independent Poisson distributions (Royle, 2004a, Royle, 2004b):

$$
f(\mathbf{y} \mid \lambda, p)=\prod_{i=1}^{R} \prod_{j=1}^{J} \operatorname{Poisson}\left(\lambda \pi_{i j}\right)
$$

where

$\mathbf{y} \quad$ is the $R \times J$ matrix of sample counts.

Model parameters $(\lambda$ and $p$ ) can be estimated in both maximum likelihood (Fiske and Chandler, 2011) and Bayesian frameworks (Kéry and Schaub, 2012).

This hierarchical model provides a flexible framework for estimating abundance. The mean abundance parameter $(\lambda)$ can be modeled as a function of site-specific covariates to draw inference on factors affecting abundance. Additionally, capture probability can be modeled as a function of both sitespecific and occasion-level covariates associated with each of the $j$ samples at site $i$.

\section{Adapting the N-Mixture Model to Estimate Fry Survival}

The $N$-mixture model as described in the preceding report section is couched in the context of site-level abundance following a Poisson distribution across sites. We considered this framework for estimating abundance at each trap site (for example, each trap or gill net site) in Lookout Point Reservoir by conducting repeated daily removal samples at each site. However, this approach posed numerous challenges. First, the set of $J$ samples at each site cannot be considered a closed sample because fish can move freely in and out of the sampling area each day. Second, because trapping relies on fish moving through the traps or nets, the spatial area over which individuals are at risk of capture is unknown, making it difficult to estimate fish density (number of fish per unit area). Third, even if sitespecific density could be estimated, estimation of reservoir-wide abundance would necessitate extrapolating from sampled to unsampled areas. For these reasons, we determined that the $N$-mixture model, as previously described, could not be used to estimate reservoir-wide abundance and survival of fry.

The use of parentage-based tagging (PBT; see section, "Fish Source, Parentage-Based Tagging, and Replication") methods for the Lookout Point Study provided an opportunity for recasting the $N$ mixture model by using information from each PBT mark. PBT identifies the offspring from each malefemale pairing, thereby providing a large number of unique batch marks. By viewing repeated sample counts as replicated across PBT batch marks instead of replicated across sampling sites, the $N$-mixture model can be used to estimate abundance of fry. Thus, if we now let $y_{i j}$ represent the number of fry captured from PBT mark $i$ on sample $j$ over all reservoir sampling locations, then $R$ is the total number of unique PBT marks, $N_{i}$ is the abundance of fry with each PBT mark, $\lambda$ is the mean abundance over all PBT marks, and $R \lambda$ is the expected value of the total abundance of fry in the reservoir. 
To estimate survival from a release group of hatchery-reared fry, we adapted the $N$-mixture model to allow for a series of monthly primary sampling occasions with secondary occasions formed from removal samples taking place over consecutive days (fig. 6). Consider a release group where $G$ is the total number of fry released into the reservoir, the number of unique PBT marks is known, the average fecundity is constant among females, and the population is sampled at some later date such that mortality occurs between release and sampling. The number of individuals with each PBT mark at the time of release, $N_{i, 0}$, is unknown, but following from equation $3, N_{i, 0}$ can be assumed to arise from a Poisson distribution with mean $G / R$. However, because the release group size is known with certainty, $N_{i, 0}$ must be viewed as a particular realization of this Poisson distribution with the constraint that $\sum_{i=1}^{R} N_{i, 0}=G$. Thus, with a known release group size, $N_{i, 0}$ for $R$ PBT marks follows a multinomial distribution with $R$ categories, sample size $G$, and equal cell probabilities of $1 / R$ :

$$
N_{1,0}, \ldots, N_{R, 0} \mid G \sim \operatorname{Multinomial}\left(G, \frac{1}{R}, \ldots, \frac{1}{R}\right) .
$$

Here, the expected value of $N_{i, 0}$ is $G / R$, equivalent to the expected value of the Poisson distribution, but the multinomial distribution satisfies the constraint $\sum_{i=1}^{R} N_{i, 0}=G$.

For a single primary sampling occasion with $S$ fraction of $G$ surviving, the number of fish with each PBT mark surviving from release to recapture $\left(N_{i}\right)$ is distributed binomially conditional on $N_{i, 0}$ :

$$
N_{i} \mid N_{i, 0} \sim \operatorname{Binomial}\left(N_{i, 0}, S\right) .
$$

The capture counts for the $i$ th PBT mark can be expressed using a multinomial distribution conditional on $N_{i}$ and conditional on the total probability of capture over $J$ secondary sampling occasions:

$$
y_{i 1}, \ldots, y_{i J} \mid N_{i} \sim \operatorname{Multinomial}\left(N_{i}, \frac{\pi_{i 1}}{\sum_{j=1}^{J} \pi_{i j}}, \ldots, \frac{\pi_{i J}}{\sum_{j=1}^{J} \pi_{i j}}\right)
$$

where $\pi_{i j}$ is the probability of first capturing an individual with PBT mark $i$ on the $j$ th sample, as described in equation 2 . 

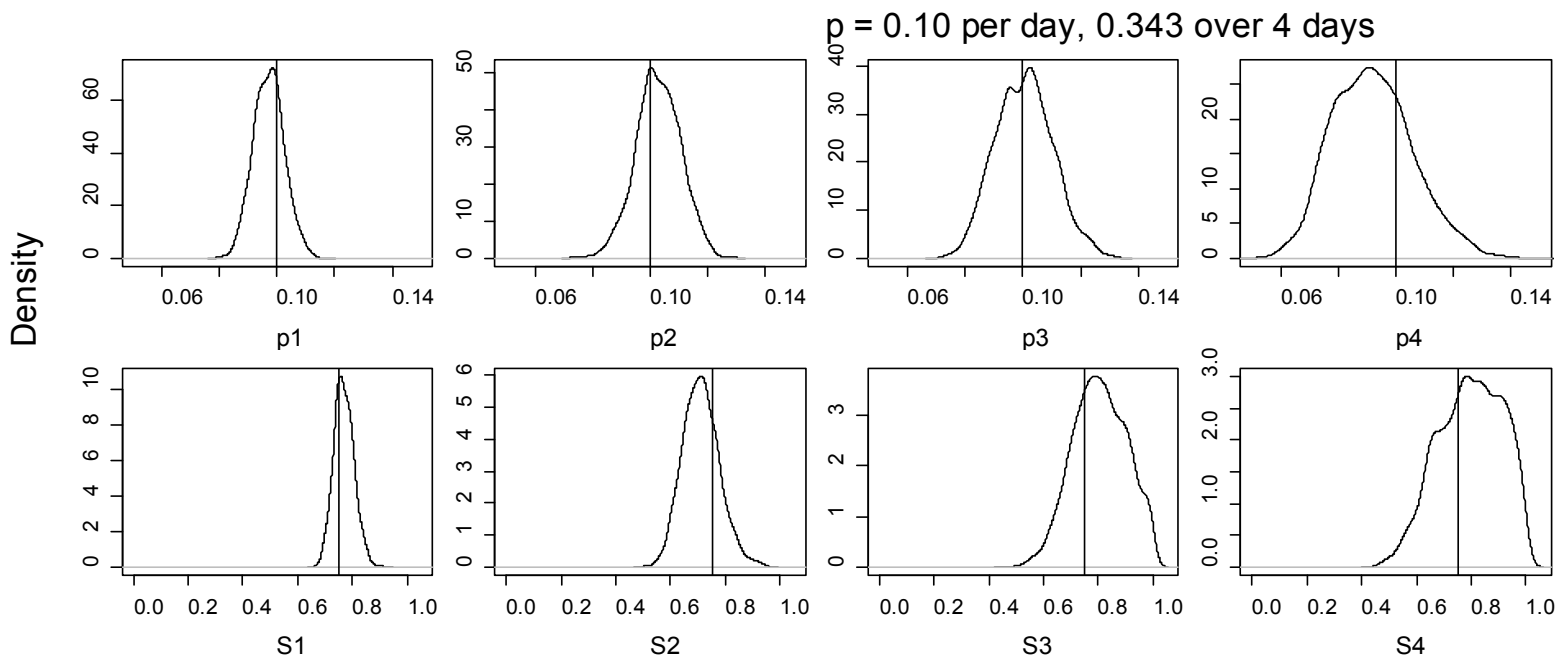

$p=0.05$ per day, 0.185 over 4 days
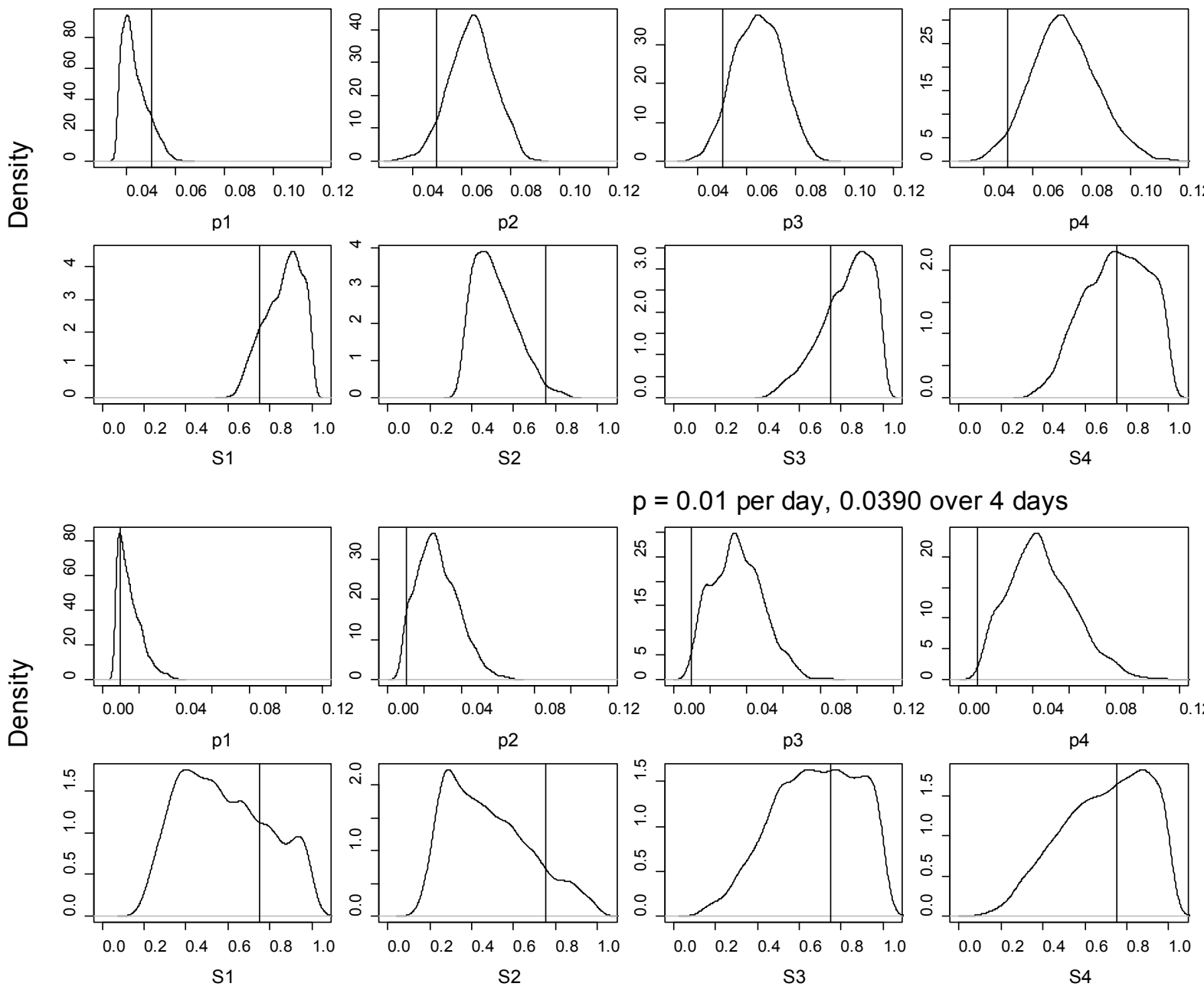

$p=0.01$ per day, 0.0390 over 4 days
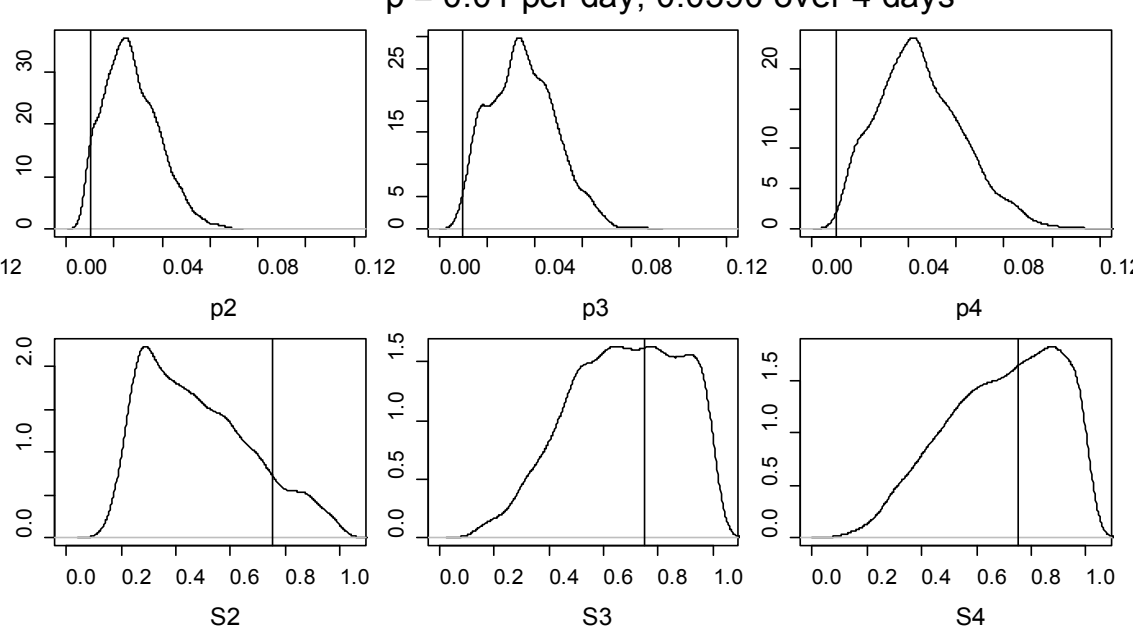

Figure 6. Posterior distributions of capture $(p)$ and survival $(S)$ probability for three simulations with $p=0.10,0.05$, and 0.01 . Vertical lines show the true parameter values used to simulate the capture data. 
To extend this study design over $K$ primary sampling occasions, the likelihood must account for removal of fry from the population at previous sampling occasions such that:

$$
N_{i, k} \mid N_{i, k-1} \sim \operatorname{Binomial}\left(N_{i, k-1}-\sum_{j=1}^{J} y_{i, j, k-1}, S_{k}\right)
$$

where $y_{i, j, 0}=0$ for all $i$ and $j$. Extending the multinomial distribution for the removal sample to $K$ primary sampling occasions, we have

$$
y_{i, 1, k}, \ldots, y_{i, J, k} \mid N_{i k} \sim \text { Multinomial }\left(N_{i k}, \frac{\pi_{i, 1, k}}{\sum_{j=1}^{J} \pi_{i, j, k}}, \ldots, \frac{\pi_{i, J, k}}{\sum_{j=1}^{J} \pi_{i, j, k}}\right) .
$$

The likelihood of the data $\left(y_{i j k}\right)$ given the parameters $\left(S_{k}\right.$ and $\left.p_{k}\right)$ of this model is the product of equation 5 with the product of equations 8 and 9 over all $K$ primary occasions and $R$ PBT marks. This model can be fit in either a maximum likelihood or Bayesian framework. Because the conditional likelihood formulation involves the unobserved latent abundance of each PBT mark $\left(N_{i k}\right)$, we decided to construct the model in a Bayesian framework where the latent abundances can be directly simulated and the parameters estimated using Markov Chain Monte Carlo (MCMC) techniques.

There are numerous assumptions under this form of the model. First, the number of individuals with each PBT mark at the time of release is not known with certainty. Given a constant average fecundity and constant survival in the hatchery, we assume that the number of individuals with each PBT mark at the time of release follows a Poisson distribution with mean $G / R$. Second, the model assumes equivalent reservoir survival and capture probabilities among PBT marks. These assumptions should be fulfilled if PBT marks are well mixed in the reservoir such that the distribution of PBT marks is similar among sampling locations. Because $y_{i j}$ represents the total number of captures over all reservoir sampling sites, $p$ now represents the proportion of each PBT marked group in the reservoir first captured on sample $j$. Thus, closure in this case means that (1) fish remain in the reservoir and are available for capture, and (2) no mortality occurs over the $J$ days of sampling.

\section{Assessment of the Parentage-Based Tagging N-Mixture Model}

To determine whether survival could be estimated without bias, we conducted a series of simulation experiments where true parameter values were assumed, capture data were simulated given the true parameter values, and the PBT $N$-mixture model was then fit to the simulated data. Given the expected study design to release 75,000 fry in the first release group, our goals were to (1) determine the minimum per-sample capture probability $(p)$ required to estimate unique capture and survival probabilities for each survival interval of a $K$-occasion experiment, and (2) identify constrained models (for example, constant $p$ or $S$ across occasions) for cases in which very low $p$ caused sparse data that led to bias in estimates of occasion-specific $p$ and interval-specific $S$. For all simulations, we assumed that a release size of $G=75,000$ fry was produced from $R=40$ unique PBT marks, which could be approximately achieved by spawning 2 males with each of 20 females having mean fecundity of 4,000 eggs $(80,000$ eggs, with some expected loss before release). This leads to an expected abundance at time of release of 1,875 fry per PBT mark. 
For the first set of simulations, we simulated data for a survival study with $K=4$ primary sampling occasions, $J=4$ days of removal sampling, and $S=0.75$ in each of the four time periods between primary occasions. We then simulated capture data for three scenarios with $p=0.10,0.05$, and 0.01 for each secondary sampling occasion. We fit the PBT $N$-mixture model to these three simulated datasets in a Bayesian framework by using a Beta $(1,1)$ prior distribution for both $p_{k}$ and $S_{k}$, and estimated unique survival and capture probabilities for each primary occasion.

We determined that the PBT $N$-mixture model was able to estimate unique detection and survival probabilities for $p=0.10$ and 0.05 , but not for $p=0.01$ (fig. 6). For $p=0.10$, the posterior distributions of $p$ and $S$ were centered around the true values. With an overall capture probability of 0.34 over four secondary sampling occasions, uncertainty in the parameters increases with each primary sampling occasion owing to a considerable fraction of the population being removed. At $p=0.05$, the posterior distributions bracket the true values but are not centered about the true values. Additionally, the posterior distributions are much broader (for example, $S_{1}$ spans $0.6-1.0$ in fig. 6). Parameter estimates for this scenario may be unbiased, and the off-center posterior distributions may be due to the particular dataset that was simulated. Nonetheless, the simulations indicate difficulty in precisely and accurately estimating $p$ and $S$ when $p=0.05$. At $p=0.01$, the posterior distributions for survival are essentially uninformative about true survival because the distributions span the range from 0 to 1 and shows some influence of uniform prior distribution.

Given that we expect capture probabilities on the order $0.01-0.02$ over a 4-day capture period ( $p$ $=0.0025-0.005)$, the PBT $N$-mixture model cannot be used to estimate occasion-specific $p$ and intervalspecific $S$. The simulations noted earlier in this section treat each primary capture occasion and survival interval as unique experiments. However, if $p$ is similar among primary sampling occasions or survival varies systematically with covariates such as fish size or time, then information across multiple primary sampling occasions may be used to fit simpler models that could potentially estimate parameters without bias when capture probabilities are low. To test these ideas, we simulated an experiment with two levels of $p$, hypothesizing that capture probabilities would differ between gear types used for capturing fish when they inhabited nearshore compared to pelagic habitats. Additionally, we hypothesized that monthly survival probabilities would increase over time as fish grow over the spring and summer. We simulated an experiment with $K=6$ primary occasions with $p=0.0025$ for the first two occasions, $p=0.0050$ for the last four primary occasions, and survival increasing over time from 0.268 in the first monthly interval to 0.817 in the last monthly interval. All other inputs were set to the same values as the previous simulations.

We fit the PBT $N$-mixture model to this simulated data using a logit link function for both $p$ and $S:$

$$
\begin{aligned}
& \operatorname{logit}\left(p_{k}\right)=b_{p, 0}+b_{p, 1} x_{p, k} \\
& \operatorname{logit}\left(S_{k}\right)=b_{S, 0}+b_{S, 1} x_{S, k}
\end{aligned}
$$

where

$b_{p, 0}$ and $b_{p, 1} \quad$ are the slope and intercept for capture probability,

$x_{p, k} \quad$ is a binary covariate set to 0 for $k=(1,2)$ and 1 for $k=(3,4,5,6)$,

$b_{S, 0}$ and $b_{S, 1} \quad$ are the slope and intercept for survival, and

$x_{S, k} \quad$ is a hypothetical covariate set to $k-1$.

We used diffuse normal prior distributions with a mean of 0 and standard deviation of 10 for all slope and intercept parameters. 
We determined that the PBT $N$-mixture model was able to estimate all parameters without bias (fig. 7). All posterior distributions bracketed the true values of the parameters and were estimated with reasonable precision as evidenced by the breadth of the posterior distributions. For example, the halfwidth of the 95 -percent credible interval ranged from 0.09 to 0.14 for the relation between survival and the hypothetical covariate (fig. 8). This analysis shows that the PBT $N$-mixture model can be used for capture probabilities as low as $0.01-0.02$ over each primary sampling occasion by expressing $p$ and $S$ as a function of covariates likely to affect these parameters.
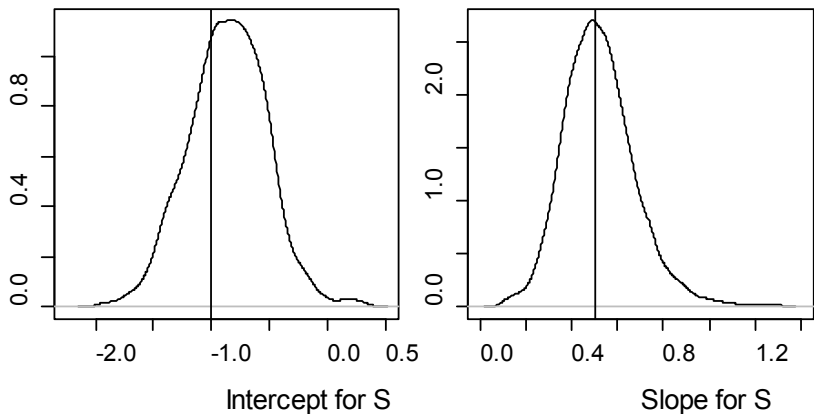

$p=0.0025$ per day for primary occasions 1 and $z$
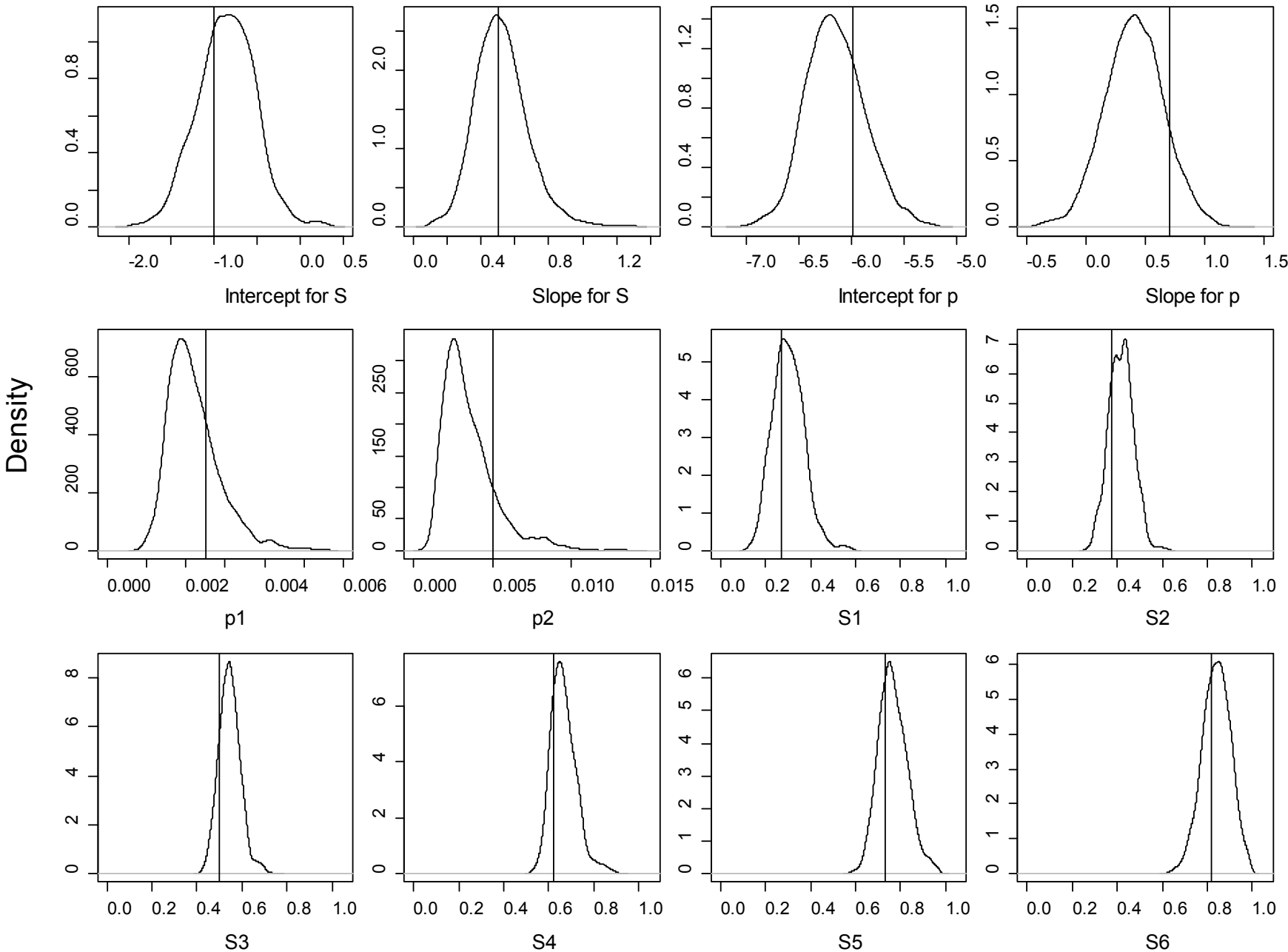

Figure 7. Posterior distributions of capture $(p)$ and survival $(S)$ probability for the simulation with two levels of capture probability and survival increasing over time. Vertical lines show the true parameter values used to simulate the capture data. 
The PBT $N$-mixture study design has two potential advantages over the staggered releaserecovery study design. First, the PBT $N$-mixture study design only requires the release of one group of hatchery-reared Chinook salmon juveniles. This is advantageous because it allows us to release a single group of fish $\left(R_{1}\right)$ in the spring and monitor their survival through time. It also alleviates concerns associated with releasing the second and third groups of fish $\left(R_{2}\right.$ and $\left.R_{3}\right)$ when release conditions are challenging, and assumptions related to their dispersal and mixing with the previous group. The second advantage is that the PBT $N$-mixture design can provide survival estimates between sampling occasions, rather than between periods when groups of fish are released, which will provide greater temporal resolution into key periods of mortality.

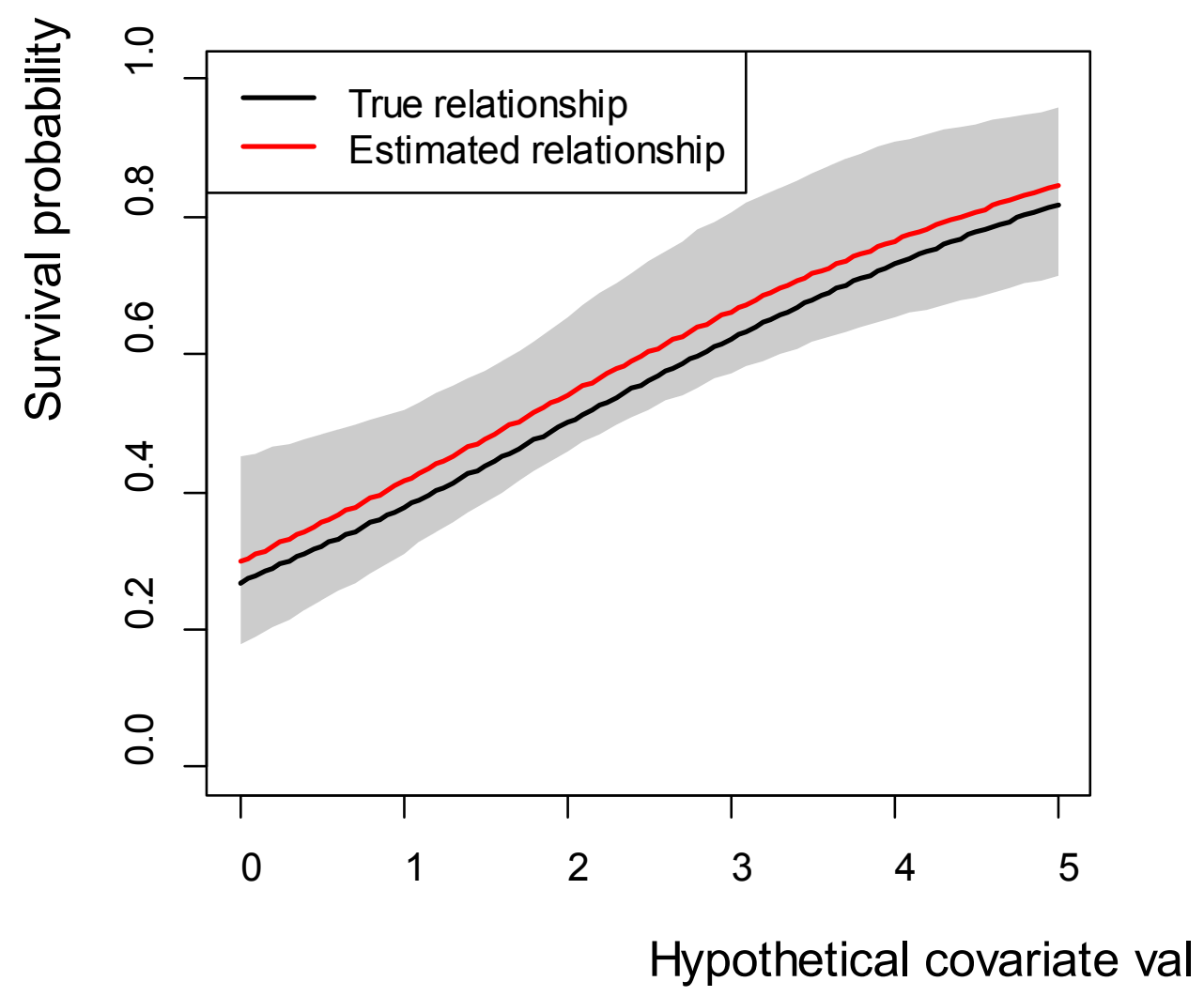

Figure 8. Graph showing true survival relationship used to simulate capture data and estimated relationship using the parentage-based tagging $\mathrm{N}$-mixture model. The gray region shows the 95 -percent credible envelope about the estimated relationship. 


\section{Implementation Plan}

\section{Fish Source, Parentage-Based Tagging, and Replication}

Fish production details were planned and organized during 2016 to ensure that Chinook salmon fry were available for release into Lookout Point Reservoir for the 2017 pilot study. Planning occurred during May-August 2016, and spawning, incubation, and rearing are anticipated during September 2016-April 2017. The Wild Fish Surrogate Program (WFSP) was identified as the lead entity responsible for producing salmon fry for the study. The WFSP produces juvenile salmon for research in the Willamette River Basin at the Smith Farm Genetics and Performance Laboratory (SFGPL) in Corvallis, Oregon. Sample size targets for our study exceeded their rearing capacity, so a plan was developed to split rearing efforts between the SFGPL and the Willamette Hatchery. Eggs and milt were to be collected from adult spring Chinook salmon at the Willamette Hatchery, and they would then be transported to the SFGPL for fertilization and incubation. All fish would hatch at the SFGPL and the $R_{1}$ group would be reared there for about 4months, and then transported to Lookout Point Reservoir and released. Spawning for the $R_{1}$ group is expected to occur during late September, hatching should occur in mid-December, and fry will be released in mid-April. The $R_{2}$ and $R_{3}$ groups will be reared at the SFGPL for about 4 months as well, and then transported to the Willamette Hatchery where they will be reared to their respective size and release date targets (table 1). Spawning for the $R_{2}$ and $R_{3}$ groups occurred on September 6, 2016, hatching should occur in mid-October, fry will be transported to the Willamette Hatchery in late-February, and releases will occur during mid-June and mid-July.

PBT methods will be used as the fish-marking technique for the pilot study (Steele and others, 2013; Sard and others, 2015). At the time of spawning, genetically distinct family groups will be created by mixing gametes from two male parents with gametes from one female parent. Genetic samples from every parent will be collected at the time of spawning. Family groups will then be assigned to specific replicates within each release group $\left(R_{1}, R_{2}\right.$ or $\left.R_{3}\right)$. The number of replicates within a given release group is based on the availability of individual rearing ponds at the SFGPL and the Willamette Hatchery - the $R_{1}$ group will be comprised of five replicates of 15,000 fry, the $R_{2}$ group will be comprised of two replicates of 25,000 fry, and the $R_{3}$ group will be comprised of two replicates of 5,000 fry. Replication within release groups will provide insights into the rearing, transportation, and release processes, so replicates will remain physically separated during these periods. Genetic samples also were collected from adult spring Chinook salmon that were outplanted upstream of Lookout Point Reservoir in 2016, so PBT also will allow us to identify naturally produced fry when they are encountered.

\section{Fish Transport and Release}

Fish loading, transport, and release protocols are critical for survival studies because the total number of fish released must be known without error (Skalski, 2016), and mortality associated with handling, transportation, and release is unacceptable. These protocols ensure that fish are held and transported in appropriate densities, that fish are properly acclimated to water temperatures at the release site prior to release, and that the release strategy maximizes the likelihood that released fish will disperse and behave in a manner consistent with naturally produced fish in the system. Data from the ODFW show that naturally produced Chinook salmon enter the reservoir during February-May and that fish are dispersed throughout the upper part of the reservoir during spring (Monzyk and others, 2015). 
The $R_{1}$ release group will be transported from the SFGPL to Lookout Point Reservoir where they will be released from a boat. On release days, a transport truck will arrive at the SFGPL to sort, load, and haul fish to Lookout Point Reservoir. At the SFGPL, replicates will be held in circular fiberglass tanks (10-ft diameter) that contain 15,000 fish apiece. Fish will be released at five separate locations in the upper part of Lookout Point Reservoir (fig. 9), so each replicate will need to be divided into groups of 3,000 fish each prior to transport. These groups will then be loaded into 231-L insulated holding containers (fig. 10). In mid-April, the $R_{1}$ fish are expected to be about $48 \mathrm{~mm}$ long and weigh $1.9 \mathrm{~g}$ apiece, so each holding container will maintain transport densities of about $18 \mathrm{~g} / \mathrm{L}$, well below the maximum standard of $50 \mathrm{~g} / \mathrm{L}$ (Surgical Protocols Steering Committee, 2011). Water temperatures at the SFGPL in mid-April are expected to be in the $10-12{ }^{\circ} \mathrm{C}$ range and surface temperatures in Lookout Point Reservoir are expected to be in the $10-11{ }^{\circ} \mathrm{C}$ range (fig. 2). Therefore, holding containers will receive oxygen during transport, but will not require heating or cooling measures to match conditions at the release sites. Transport time from the SFGPL to Lookout Point Reservoir is expected to be about 90 minutes. Transport containers will be moved from the fish hauling truck to a boat on the reservoir and then taken upstream of Lookout Point, near Hampton Campground (fig. 9). The first group of 3,000 fish will be released at this location, in the middle of the river, and these fish will disperse downstream into the reservoir. The boat will then move downstream and release the remaining four groups at nearshore locations between the head of the reservoir and the mouth of School Creek (fig. 9). This release strategy is designed to distribute fish throughout the upper part of Lookout Point Reservoir to mimic fry distributions previously observed in the ODFW sampling (Monzyk and others, 2015). This process will be repeated for each replicate during the course of 2 days until all fish from the $R_{1}$ group have been released.

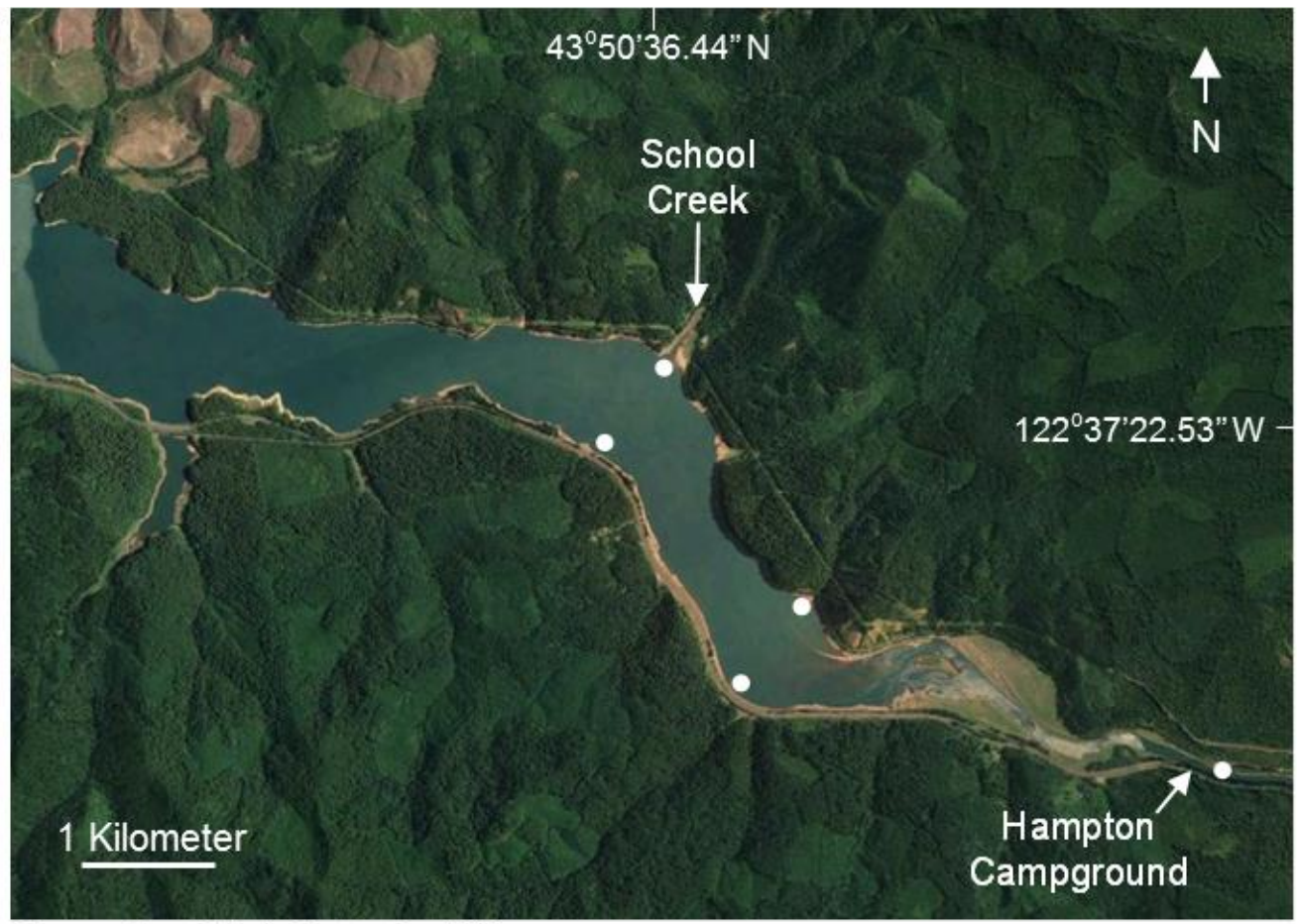

Source: GoogleEarth September 2016

Figure 9. Orthoimage showing five release sites (white circles) for juvenile Chinook salmon in the upper part of Lookout Point Reservoir, western Oregon, during mid-April 2017. Hampton Campground and School Creek also are shown as reference points. 


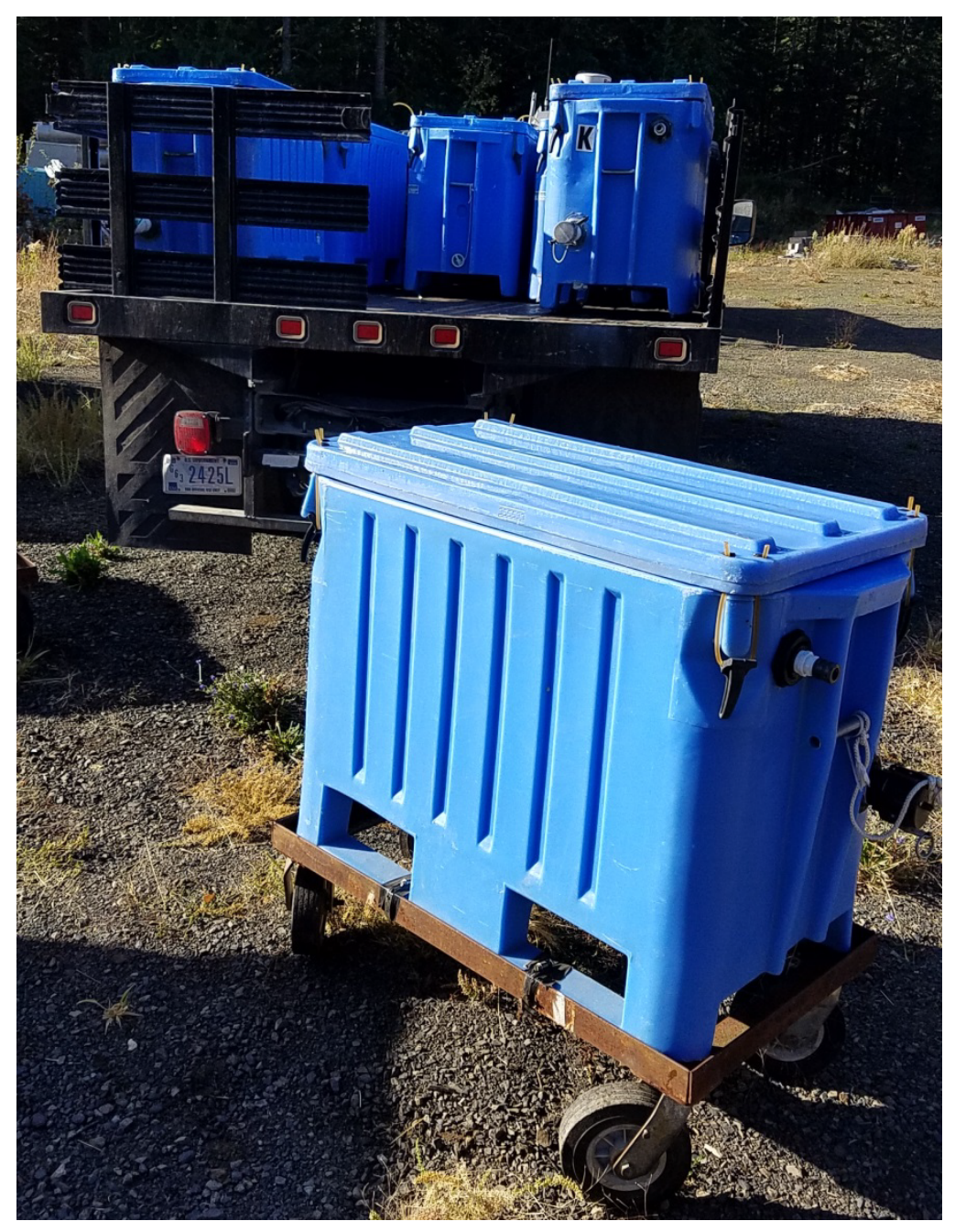

Figure 10. Photograph showing insulated fish-holding containers that will be used to transport juvenile Chinook salmon to Lookout Point Reservoir, western Oregon, during 2017. In the foreground a single container is shown on a wheeled platform and, in the background, five containers are shown in a fish transport truck.

The $R_{2}$ and $R_{3}$ releases will be more challenging because they are scheduled for June and July, when Lookout Point Reservoir is thermally stratified (fig. 2). Juvenile salmon would be expected to avoid warm surface water in the reservoir during summer, and this has been confirmed by the ODFW in their sampling. During summer, gill nets are placed 30-60 ft below the water surface to target the segment of the water column being used by juvenile Chinook salmon (Monzyk and others, 2015). The $R_{2}$ and $R_{3}$ release strategy must account for warm surface temperatures and use release techniques that avoid thermally shocking released fish. Water temperatures at the Willamette Hatchery, where $R_{2}$ and $R_{3}$ fish will be held, are expected to be in the $13-15^{\circ} \mathrm{C}$ range during June and July 2017 (Dan Peck, Oregon Department of Fish and Wildlife, written commun., August 8,2016), and data collected by the ODFW suggest that juvenile salmon in the reservoir will be using water temperatures in the $15-17^{\circ} \mathrm{C}$ range. However, surface temperatures will be in the $18-21^{\circ} \mathrm{C}$ range, so a release apparatus will be used to release fish from a boat and inject them 30-60 ft below the surface, without exposing them to the warm surface water. This device will use a submersible pump to pull cool water from lower segments of 
the water column into a headbox that will feed water through a release pipe (10.2-cm diameter). The pipe will extend from the surface down through the warm surface water and can be adjusted to release fish at desired depths.

The $R_{2}$ and $R_{3}$ releases will be conducted in the lower two-thirds of Lookout Point Reservoir, where Chinook salmon fry typically reside during summer (Monzyk and others, 2015). Releases of each group will occur at five locations to mimic distributions previously observed (fig. 11). The $R_{2}$ fish will be held in two replicate groups containing 25,000 fish apiece at the Willamette Hatchery. In mid-June, fish are expected to be about $97 \mathrm{~mm}$ long (table 1) and weigh $11.4 \mathrm{~g}$ apiece, so each replicate will need to be sorted into smaller groups for transport on each release day. We plan to transport $R_{2}$ fish in 1,000 fish groups, in holding densities of $50 \mathrm{~g} / \mathrm{L}$. Each group will be loaded into an insulated holding container (fig. 10), transported by truck to the reservoir, and then transferred onto a boat. The boat will then take fish to the release sites (fig. 9) where they will be released using the release apparatus. The identical process will occur for $R_{3}$ releases with the exception of numbers of fish transported in each holding container $-R_{3}$ fish are expected to be $120 \mathrm{~mm}$ long and weigh $20.1 \mathrm{~g}$, so fish will be sorted in 500 fish groups (holding density $=44 \mathrm{~g} / \mathrm{L}$ ).

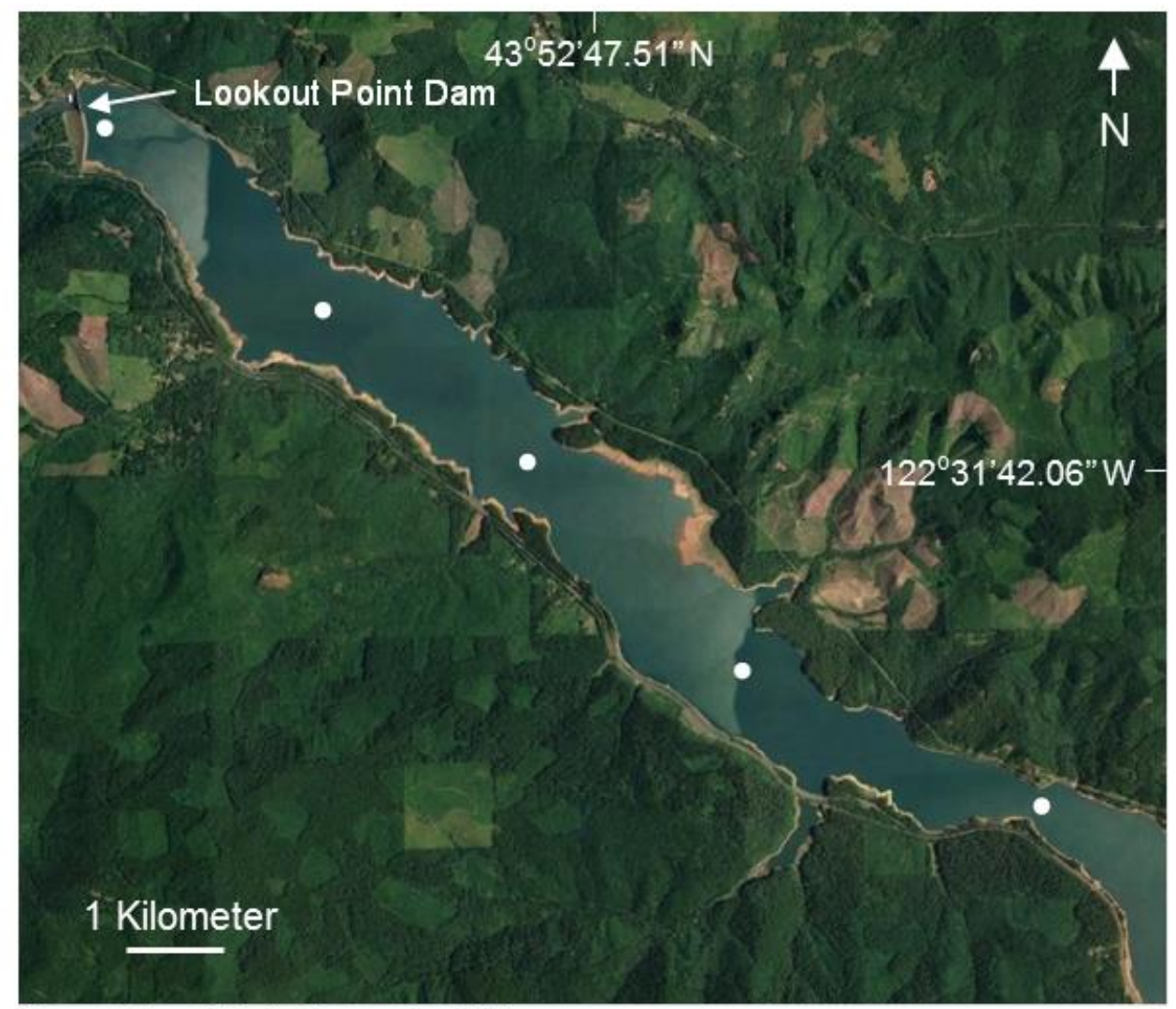

Source: GoogleEarth September 2016

Figure 11. Orthoimage showing five release sites (white circles) for juvenile Chinook salmon in Lookout Point Reservoir, western Oregon, during mid-June and mid-July 2017. Lookout Point Dam also is shown as a reference point. 


\section{Reservoir Sampling}

Sampling will occur 1 week per month during April-October 2017. To estimate catch rates for the 2017 pilot study, we examined data from Lookout Point Reservoir in 2014 when 67,313 hatcheryproduced Chinook salmon fry were outplanted. We used fish-length data from Chinook salmon fry in Lookout Point Reservoir (Monzyk and others, 2015) and length-based survival estimates from Zabel and others (2005) to estimate the number of fry that were alive in the reservoir at the end of each month during July-November (table 2). We then used monthly collection data from Monzyk and others (2015) to obtain estimates for the proportion of the live population that was captured during each monthly sampling period. This analysis determined that average catch rates were 2.1 fish per gill net set and estimated that monthly capture probabilities were about 0.006 (table 2). Our goal for the 2017 pilot study is to develop a sampling strategy that will allow us to achieve total capture probabilities in the 0.01-0.02 range. To accomplish this, we estimate that each sampling period will require about 40 gill net sets per night during the 4-day sampling interval. This would result in an overall effort of 160 gill net sets per month and will likely require four 2-person crews. On the first day of sampling each month, sampling gear (gill nets or shoreline traps) will be deployed in the reservoir and allowed to fish for about $24 \mathrm{~h}$. Crews will remove fish daily and redeploy the sampling gear for a total of four consecutive sampling days. Collected fish will be enumerated, identified to species, and preserved for PBT processing after the study.

Table 2. Estimated population of hatchery-produced juvenile Chinook salmon in Lookout Point Reservoir, western Oregon, 2014.

[ODFW, Oregon Department of Fish and Wildlife

\begin{tabular}{lccccc}
\hline Month & $\begin{array}{c}\text { Estimated } \\
\text { population }\end{array}$ & $\begin{array}{c}\text { Number of gill } \\
\text { nets placed by } \\
\text { ODFW }\end{array}$ & $\begin{array}{c}\text { Number of juvenile } \\
\text { Chinook salmon } \\
\text { collected }\end{array}$ & $\begin{array}{c}\text { Average number of } \\
\text { fish captured per net } \\
\text { placed }\end{array}$ & $\begin{array}{c}\text { Estimated proportion of } \\
\text { population captured }\end{array}$ \\
\hline July & 40,232 & 60 & 195 & 3.3 & 0.005 \\
August & 26,090 & 43 & 125 & 2.9 & 0.005 \\
September & 17,737 & 46 & 66 & 1.4 & 0.004 \\
October & 12,579 & 56 & 76 & 1.4 & 0.006 \\
November & 9,425 & 56 & 74 & 1.3 & 0.008 \\
& Average & 52.2 & 107.2 & 2.1 & 0.006 \\
\hline
\end{tabular}

A combination of electrofishing, gill nets, and nearshore traps will be used to sample Chinook salmon fry in the reservoir during the pilot study (fig. 12). Monzyk and others (2015) reported that 7290 percent of the subyearling Chinook salmon captured during April and May in Lookout Point Reservoir were located in the upper part of the reservoir, whereas the proportion captured in the lower part of the reservoir was small (2-4 percent). We will use this information in our sampling strategy. April and May sampling will be conducted using floating box traps, Oneida Lake traps, and shoreline electrofishing because Chinook salmon fry are shoreline-oriented during this period (Monzyk and others, 2015). We will sample throughout the reservoir in April and May, but will apply greater effort (more sampling equipment) in the upper part of the reservoir where Chinook salmon fry are expected to be concentrated. June is a transition month when fry begin moving offshore while others remain along the shorelines. We will use a combination of sampling techniques during this period including nearshore traps, electrofishing, and gill nets. Less is known about the longitudinal distribution of Chinook salmon fry in the reservoir during this period because the ODFW has not traditionally sampled during June. 
Therefore, sampling will occur throughout the reservoir during June. We will sample exclusively with gill nets during July-October because juvenile Chinook salmon fry will be offshore during this period. Sampling will be conducted throughout most of the reservoir, but we will avoid areas upstream of School Creek in July and August as the ODFW has shown that Chinook salmon fry are absent from that area of the reservoir in those months (Monzyk and others, 2015).

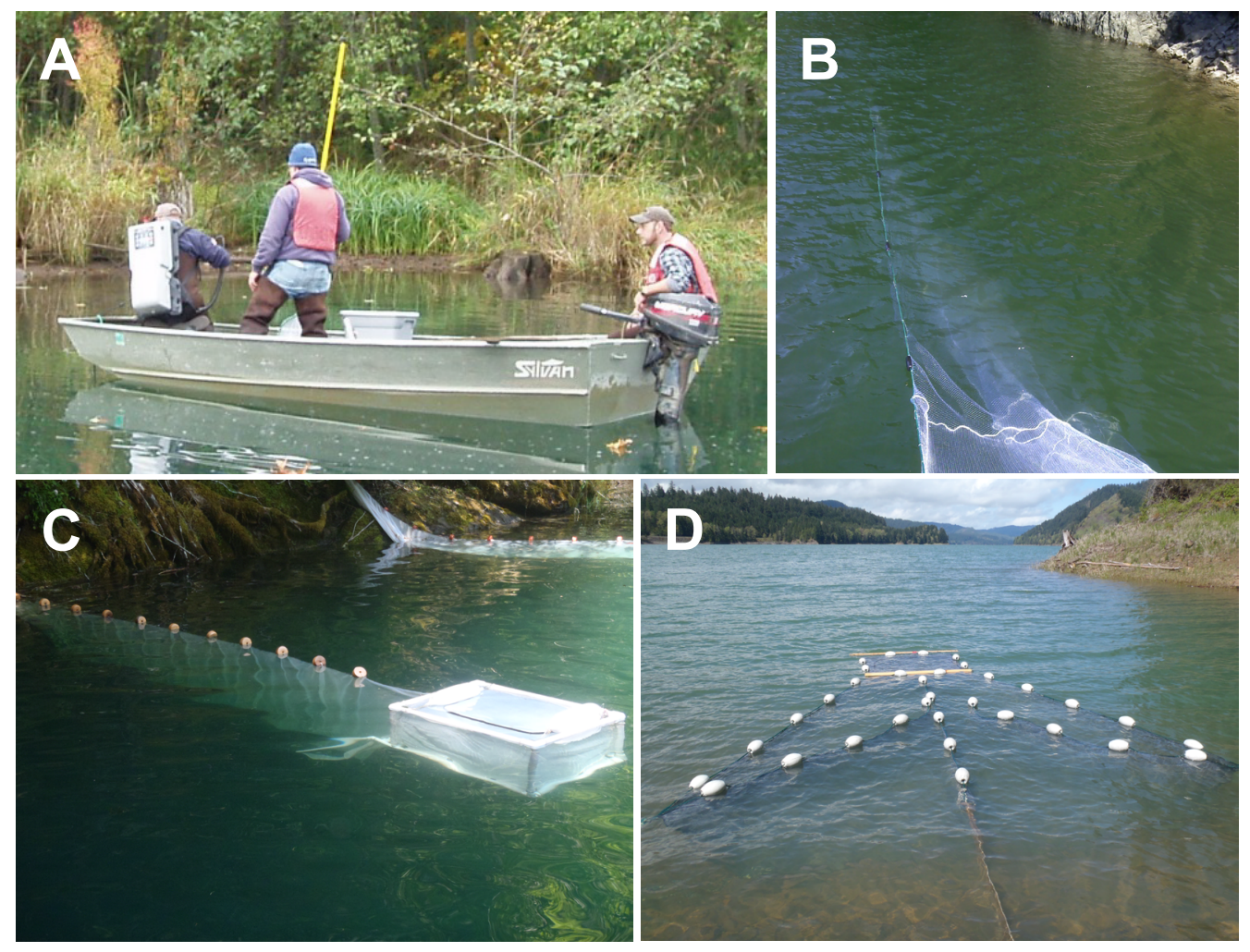

Figure 12. Photographs of sampling equipment, including boat electrofishing $(A)$, gill nets $(B)$, floating box traps (C), and Oneida Lake traps (D), that will be used in Lookout Point Reservoir, western Oregon, 2017.

\section{Critical Uncertainties}

In theory, the staggered release-recovery model and PBT $N$-mixture model are conceptually sound techniques for estimating fry survival in Lookout Point Reservoir, but field testing will be required to address a series of critical uncertainties and model assumptions. The staggered releaserecovery model will use three releases of hatchery-reared fish to generate survival estimates that will be used to make inferences about survival of Chinook salmon fry in the reservoir. However, one key assumption of the staggered release-recovery model is that survival of the two release groups is the same in the time period following release of the second group. It may be challenging to produce hatchery-reared Chinook salmon juveniles that match the body size, behavior, and dispersal patterns of naturally produced fish. Furthermore, the second release group will be naïve to the natural environment, whereas the survivors of the first release group will have already reared for a substantial period of time in the reservoir. Therefore, survival of the second release group may differ from that of the first group. 
Another key assumption is that capture probabilities are the same among release groups, which implies that the release groups must be well-mixed such that they have a similar spatial distribution throughout the reservoir. We are planning a rigorous sampling effort that will include spatial and temporal replication, and we will assess for differences in dispersal patterns between the two populations to assess this assumption. Furthermore, hatchery-produced juveniles will be released into the reservoir in three groups, and these will be distinguishable using PBT methods. This will allow us to further assess differences in dispersal patterns among hatchery-produced release groups.

The PBT $N$-mixture model has assumptions and critical uncertainties that differ from those of the staggered release-recovery design. The key assumption of the PBT $N$-mixture model is that capture and survival probabilities are similar among PBT mark groups, which implies that fish from all marks have a similar spatial distribution throughout the reservoir. This assumption can be achieved with careful rearing and release strategies that ensure that all PBT groups have a similar spatial distribution among release sites. Two critical uncertainties of the PBT $N$-mixture model are (1) whether the study will achieve capture probabilities of 1-2 percent over each primary sampling occasion, and (2) whether key covariates will be able to explain variation in survival and capture probability among sampling occasions.

Low capture probability of Chinook salmon juveniles is a primary concern for both approaches. We have examined existing datasets to estimate reservoir populations and related those datasets to catch data from previous years. These results were used to develop estimates for effort required to achieve our collection goals in 2017, and we plan to implement sampling at a level not previously attempted in Lookout Point Reservoir. However, the outcome of this sampling strategy remains to be seen. We believe that the planned efforts will achieve our sampling goals, but insufficient collection of Chinook salmon fry will limit the ability to estimate survival using either of our proposed approaches.

By applying two analytical methods for estimating survival, each with different assumptions and uncertainties, we anticipate gaining much more information about survival than using either method alone. Estimates from each method can be compared to help understand and assess the performance of each model. For example, because the PBT $N$-mixture model does not require multiple release groups, we may be able to assess the assumption of equal survival between the two release groups in the staggered release-recovery design. Likewise, because the PBT $N$-mixture model must rely on covariates to estimate variation in survival among primary sampling periods, these estimates can be compared to those from the staggered release-recovery model to evaluate whether the survival estimates are similar.

\section{Summary}

We plan to evaluate the staggered release-recovery and PBT $N$-mixture study designs during a pilot study in Lookout Point Reservoir, western Oregon, in 2017. Much is known about fish populations and distributions in the reservoir, but little is known about survival of Chinook salmon (Oncorhynchus tshawytscha) fry, and this information will be critical for fishery managers in the future. The two approaches seem to offer promising capabilities, but neither has been field-tested. The 2017 pilot study will provide information on the performance of these study designs, and also should yield important insights into sampling approaches because we will be implementing fish collection efforts at levels that are unprecedented in Willamette Project (Project) reservoirs. This level of collection effort was selected to provide the best opportunity for collecting sufficient numbers of Chinook salmon fry to obtain meaningful survival estimates. There may be additional benefits from these collection efforts as well. For example, we should be able to rigorously evaluate proportions of catch at each sampling location to determine if there are differences in distribution patterns of salmon fry from $R_{1}, R_{2}, R_{3}$ and naturally produced groups. Our sampling methods likely will preclude by-catch of adult piscivorous fish species, 
but we may collect juvenile piscivorous fish and could potentially learn more about their distribution within Lookout Point Reservoir. When encountered, we will enumerate juvenile piscivorous fish, identify them to species, collect fork-length data, and record their location of capture. We also will be lethally sampling fish to meet the removal requirements of the study designs we are testing, and to collect DNA samples for PBT analysis. Thus, we expect to have large numbers of samples available if other researchers are interested in examining isotope ratios within the fish community, or applying other tissue-based research methodologies in the future. The side-by-side comparison of the two approaches will allow us to evaluate strengths and weaknesses, and to compare survival estimates from each approach. This process will be insightful for future development of similar techniques that can be used throughout the Project and at other locations where survival information of salmon fry is desired.

\section{References Cited}

Beeman, J.W., Hansel, H.C., Hansen, A.C., Evans, S.D., Haner, P.V., Hatton, T.W., Kofoot, E.E., Sprando, J.M., and Smith, C.D., 2014, Behavior and dam passage of juvenile Chinook salmon at Cougar Reservoir and Dam, Oregon, March 2012-February 2013: U.S. Geological Survey Open-File Report 2014-1177, 52 p.

Brandt, J.R., Monzyk, F.R., Romer, J.D., and Emig, R., 2016, Status and trends of predator species in Lookout Point Reservoir: Report by the Oregon Department of Fish and Wildlife to the U.S. Army Corps of Engineers, $44 \mathrm{p}$.

Dorazio, R.M., Jelks, H.L., and Jordan, F., 2005, Improving removal-based estimates of abundance by sampling a population of spatially distinct subpopulations: Biometrics, v. 61, no. 4, p. 1,093-1,101.

Fiske, I., and Chandler, R., 2011, Unmarked-a R package for fitting hierarchical models of wildlife occurrence and abundance: Journal of Statistical Software, v. 43, no. 10, p. 1-23, accessed 2014, at http://www.jstatsoft.org/v43/i10/.

Keefer, M.L., Taylor, G.A., Garletts, D.F., Helms, C.K., Gauthier, G.A., Pierce, T.M., and Caudill, C.C., 2013, High-head dams affect downstream fish passage timing and survival in the Middle Fork Willamette River: River Research and Applications, v. 29, p. 483-492.

Kéry, M., and Royle, J.A., 2016, Applied hierarchical modeling in ecology-Analysis of distribution, abundance and species richness in R and BUGS (1st ed.): Academic Press and Elsevier, 808 p.

Kéry, M., and Schaub, M., 2012, Bayesian population analysis using WinBUGS (1st ed.): Elsevier, 537 p.

Kock, T.J., Beeman, J.W., Hansen, A.C., Hansel, H.C., Hansen, G.S., Hatton, T.W., Kofoot, E.E., Sholtis, M.D., and Sprando, J.M., 2015, Behavior, passage, and downstream migration of juvenile Chinook salmon from Detroit Reservoir to Portland, Oregon, 2014-15: U.S. Geological Survey OpenFile Report 2015-1220, 40 p.

Lady, J.M., Westhagen, P., and Skalski, J.R., 2003, SampleSize 1.1—Sample size calculations for fish and wildlife survival studies: Seattle, University of Washington School of Aquatic and Fishery Science, accessed November 2016, at http://www.cbr.washington.edu/analysis/apps/samplesize.

Monzyk, F.R., Emig, R., Romer, J.D., and Friesen, T.A., 2015, Life-history characteristics of juvenile spring Chinook salmon rearing in Willamette Valley reservoirs: Report by the Oregon Department of Fish and Wildlife to the U.S. Army Corps of Engineers, $56 \mathrm{p}$.

Muir, W.D., Smith, S.G., Williams, J.G., Hockersmith, E.E., and Skalski, J.R., 2001, Survival estimates for migrant yearling Chinook salmon and steelhead tagged with passive integrated transponders in the lower Snake and lower Columbia Rivers, 1993-1998: North American Journal of Fisheries Management, v. 21, p. 269-282. 
National Oceanic and Atmospheric Administration, 2008, Endangered Species Act section 7(a)(2) consultation biological opinion and Magnuson-Stevens Fishery Conservation and Management Act essential fish habitat consultation-Consultation on the Willamette River Basin Flood Control Project: National Oceanic and Atmospheric Administration Fisheries Log Number FIWR12000/02117, June 11, 2008., accessed May 2015, at http://www.nwr.noaa.gov/Salmon-Hydropower/WillametteBasin/Willamette-BO.cfm.

Perry, R.W., Skalski, J.R., Brandes, P.L., Sandstrom, P.T., Klimley, P., Ammann, A., and MacFarlane, B., 2010, Estimating survival and migration route probabilities of juvenile Chinook salmon in the Sacramento-San Joaquin River Delta: North American Journal of Fisheries Management, v. 30, p. $142-156$.

Romer, J.D., and Monzyk, F.R., 2014, Predatory fish in Lookout Point and Foster reservoirs: Presentation at the U.S. Army Corps of Engineers' Willamette Basin Fisheries Science Review, Portland, Oregon, accessed April 27, 2016, at http://odfw.forestry.oregonstate.edu/willamettesalmonidrme/reservoir-research-publications.

Royle, J.A., 2004a, N-mixture models for estimating population size from spatially replicated counts: Biometrics, v. 60, p. 108-115.

Royle, J.A., 2004b, Generalized estimators of avian abundance from count survey data: Animal Biodiversity and Conservation, v. 27, p. 375-386.

Sard, N.M., O’Malley, K.G., Jacobson, D.P., Hogansen, M.J., Johnson, M.A., and Banks, M.A., 2015, Factors influencing spawner success in a spring Chinook salmon (Oncorhynchus tshawytscha) reintroduction program: Canadian Journal of Fisheries and Aquatic Sciences, v. 72, p. 1,390-1,397.

Skalski, J.R., 2016, Review of tagging study designs to estimate reservoir passage survival in the Willamette Valley Project: Report for the U.S. Army Corps of Engineers, 38 p.

Skalski, J.R., Buchanan, R.A., and Griswold, J., 2009, Review of marking methods and releaserecapture designs for estimating the survival of very small fish-Examples from the assessment of salmonid fry survival: Reviews in Fisheries Science, v. 17, p. 391-401.

Skalski, J.R., Smith, S.G., Iwamoto, R.N., Williams, J.G., and Hoffman, A., 1998, Use of passive integrated transponder tags to estimate survival of migrant juvenile salmonids in the Snake and Columbia Rivers: Canadian Journal of Fisheries and Aquatic Sciences, v. 55, p. 1,484-1,493.

Skalski, J.R., Weiland, M.A., Ham, K.D., Ploskey, G.R., McMichael, G.A., Colotelo, A.H., Carlson, T.J., Woodley, C.M., Eppard, M.B., and Hockersmith, E.E., 2016, Status after 5 years of survival compliance testing in the Federal Columbia River Power System (FCRPS): North American Journal of Fisheries Management, v. 36, p. 720-730.

Steele, C.A., Anderson, E.C., Ackerman, M.W., Hess, M.A., Campbell, N.R., Narum, S.R., and Campbell, M.R., 2013, A validation of parentage-based tagging using hatchery steelhead in the Snake River Basin: Canadian Journal of Fisheries and Aquatic Sciences, v. 70, p. 1,046-1,054.

Surgical Protocols Steering Committee, 2011, Surgical protocols for implanting JSATS transmitters into juvenile salmonids for studies conducted for the U.S. Army Corps of Engineers: Surgical Protocols Steering Committee, $18 \mathrm{p}$.

Zabel, R.W., Wagner, T., Congleton, J.L., Smith, S.G., and Williams, J.G., 2005, Survival and selection of migrating salmon from capture-recapture models with individual traits: Ecological Applications, $\mathrm{v}$. 15 , p. $1,427-1,439$. 

Publishing support provided by the U.S. Geological Survey

Science Publishing Network, Tacoma Publishing Service Center

For more information concerning the research in this report, contact the Director, Western Fisheries Research Center U.S. Geological Survey

6505 NE 65th Street

Seattle, Washington 98115

http://wfrc.usgs.gov/ 
를

흠

雪

올

을

뮬

罗

鲁

के

寅

ㅊ..ㄹ.

8

을

을

届

옹

콕

웅 